\title{
INVENTARIO DE INMUEBLES PATRIMONIALES EN \\ EL SECTOR DE LOS CAÑOS DEL MERCADO PÚBLICO (CARRERAS 40 A 46) - BARRANQUILLA'
}

Artículo de investigación - Recibido: 15 de Febrero de 2016 - Aceptado: 20 de Mayo de 2016

\author{
Jairo López Martínez²
}

Universidad de la Costa CUC. Barranquilla - Colombia. jlopez@cuc.edu.co

Para citar este artículo / to reference this article:

López, J. (2016). Inventario de inmuebles patrimoniales en el sector de los caños del mercado público (Carreras 40 a 46) - Barranquilla. Módulo Arquitectura CUC, Vol.17 N¹, 75-114.

\section{Resumen}

El presente artículo producto de investigación tiene como objetivo presentar los resultados sobre el análisis del inventario de inmuebles patrimoniales en la zona de los caños del Mercado Público (Carrera 40 a la carrera 46) sobre el borde oriental del mismo (calle 10) - en el sector de Barranquillita de la ciudad de Barranquilla, acorde con los proyectos de intervención de las plazas Ujueta y el edificio de la Intendencia Fluvial, apoyándonse en conceptos y lineamientos establecidos en los documentos internacionales sobre patrimonio arquitectónico, y en la normatividad colombiana, y los planes establecidos en el Plan de Desarrollo de la ciudad de Barranquilla.

\section{Palabras clave}

Inventario, inmuebles patrimoniales, valoración, significación cultural, indicadores de patrimonio, cartografía,

1 Articulo producto de la investigación terminada en el año 2014 llamada Inventario de inmuebles patrimoniales en el sector de los caños del mercado entre carreras 40 y carreras 46 en la ciudad de Barranquilla.

2 Arquitecto egresado de la Universidad de la Costa CUC, especialista en Patrimonio y docente de tiempo completo de la Facultad de Arquitectura de la Universidad de la Costa CUC. 


\title{
INVENTORY OF PATRIMONIAL PROPERTY IN THE PUBLIC MARKET SECTOR (CARRERAS 40 A 46) - BARRANQUILLA
}

\begin{abstract}
The present article research product aims to present the results on the analysis of the inventory of heritage properties in the area of public market pipes (Race 40 to race 46) on the eastern edge of it (street 10) - in the Barranquillita sector of the city of Barranquilla, according to the intervention projects of the Ujueta squares and the Intendencia Fluvial building, supported by concepts and guidelines established in the international documents on architectural heritage, and in Colombian regulations, and plans Established in the Development Plan of the city of Barranquilla
\end{abstract}

\section{Keywords}

Inventory, heritage properties, valuation, cultural significance, heritage, cartography, indicators 


\section{Introduccion}

La zona de Barranquillita, y en especial el área correspondiente al borde oriental del caño del Mercado Público de la ciudad de Barranquilla, localizados entre las carrera 40 a la carrera 46 y entre las calle 10 y calle 6 , por varias décadas ha permanecido abandonada. Esta realidad ha permitido el deterioro del sector antes mencionado, lo cual, ha sumido en un estado de subdesarrollo, con muchas de sus estructuras históricas abandonadas o demolidas. Es claro, determinar el grado de inseguridad que reina en esta zona, por la soledad y el deterioro físico ambiental; en donde la población flotante en la mañana y escazas horas de la tarde es enorme, como consecuencia de la gran actividad comercial de productos de la canasta familiar. El Centro histórico y la zona del mercado público de la ciudad de Barranquilla poseen un significativo potencial patrimonial, representado en edificaciones de diferentes estilos y tipologías. En el presente, la Administración Distrital está desarrollando una serie de proyectos de gran envergadura en la zona, tales como: El Corredor Portuario; La Avenida del Río (Isla La Loma); El Portal de Transmetro Barranquillita; La Plaza y Restauración del Edificio de la Intendencia Fluvial; El
Nuevo Espacio Público de San Andresito; Los Sistemas de Plazas para Renovación Urbana (Plaza Ujueta) y la Prolongación de la Carrera 50, y todos estos proyectos tienen una incidencia directa con el sector en estudio. Las políticas del Distrito de Barranquilla relacionadas con la recuperación del centro histórico, y su área adyacente tiende a favorecer el desarrollo de proyectos de tipo vial, de recuperación de edificaciones patrimoniales y mejoramiento del espacio público, que se ve evidenciado en el crecimiento y provecho del sector de la economía. (Secretaria de Planeacion de Barranquilla, 2012) No obstante, no ha sido posible definir o implementar un sistema de recuperación del espacio público en la zona de Barranquillita, junto con sus edificaciones con un alto valor patrimonial ubicadas en el área de los caños del mercado público, que permita mostrar la pureza y belleza de sus estilos redefinir su funcionamiento interno y minimizar el impacto visual negativo que ayudan al deterioro ambiental del espacio público.

La intervención en el patrimonio edificado, ha ampliado su perspectiva para abarcar escalas y ámbitos de lo edilicio, lo urbano y lo territorial, es un campo de estudio y ejercicio que 
requiere de conocimiento y método. (Tello, 2013)

En el proyecto de inventario se pretende, Identificar, cuantificar y analizar las edificaciones con características patrimoniales; desarrollar una matriz cuyo contenido tiene en cuenta todo lo relacionado con el entorno circundante, es decir, análisis de las patologías de las manzanas; la valoración del contexto urbano construido; el valor ambiental, estético, simbólico y tecnológico urbano del sitio, a manera de establecer que no solo las edificaciones son patrimonio, sino también el territorio que las contiene, para luego elaborar un análisis por componentes tipo FODA, que ayude a la clarificación del concepto de "conservación de los centros históricos y los factores que influyen en su conservación", y a la identificación de los indicadores de patrimonio, que sirvan de apoyo para la preservación de las edificaciones con valor patrimonial y por ende para la recuperación de los espacios públicos urbanos en los que se encuentran; además como material de apoyo al Observatorio de la Ciudad. La restauración tiene como fin conservar y revelar los valores estéticos e históricos de las edificaciones y se fundamenta en el y las partes auténticas de los mismos. A partir de la Ley 388 de 1997 (Ley de Ordenamiento Territorial), se establecieron cinco dimensiones para sustentar la estructura del ordenamiento del territorio: cultural, política, económica, social y ambiental. En la dimensión cultural, como componente estructurante, se propuso considerar el patrimonio cultural $y$, dentro de éste, en posición destacada, el patrimonio inmueble. A su vez, este último concreta en el territorio geográfico, de municipios y regiones, las expresiones tangibles de las otras dimensiones. (República de Colombia, Ministerio de Cultura, 2005)

La ley 1185 de 2008, que amplía y modifica la Ley General de cultura, que establece que la política referente al Patrimonio Cultural de la Nación tendrá como objetivos principales la salvaguardia, protección, recuperación, conservación, sostenibilidad y divulgación del mismo, con el propósito de que sirva como testimonio de la identidad cultural nacional, tanto en el presente como en el futuro, y estableció ámbitos de Bienes de Interés Cultural permitiéndole a la Nación y a las entidades territoriales el reconocimiento, la protección y el manejo de los mismos, mediante la aplicación de declaratorias de 
carácter nacional, departamental, distrital, municipal y de territorios indígenas por parte de los respectivos gobiernos. Es a partir de estas teorías que se sustenta la argumentación del proyecto. Teniendo en cuenta que el valor cultural de cualquier edificación permite que esta pueda ser protegida mediante una declaratoria como Bien de Interés Cultural, con la respectiva inscripción en el Régimen de Protección o de Salvaguardia previsto en la ley, según los criterios de: antigüedad, autoría, autenticidad, constitución del bien, forma, estado de conservación, contextos ambiental, físico y urbano y la representatividad y contextualización sociocultural, se pretende llenar el vacío de la situación en que se encuentran tanto la zona, como las edificaciones o inmuebles patrimoniales ubicados en la zona de los caños del mercado público, sector de Barranquillita, de la ciudad de Barranquilla.

En el proyecto de inventario se pretende, Identificar, cuantificar y analizar las edificaciones con características patrimoniales, a fin de lograr una re significación y recuperación de la estructura urbana del sector de Barranquillita, lo cual se puede establecer como punto de partida de una acción conservacionista ya que apunta a la valoración del patrimonio inmueble. La identificación del inmueble, define un enfoque de análisis que si bien es cierto, tiene origen en el inmueble mismo, debe obligatoriamente reconocer el contexto en su sentido más amplio, no solo por los valores de imagen, paisaje y conjunto, si no por las implicaciones que cualquier decisión implicaría para los procesos de transformación y/o deterioro urbano, paisajístico y territorial.

La elaboración de Inventarios de patrimonio, muestra la importancia que para una sociedad tiene el identificar y proteger sus bienes de interés cultural. Estos inventarios implican procedimientos valorativos que buscan no solo identificar sino comprender, jerarquizar, clasificar y evaluar de manera individualizada y en conjunto, aquellos bienes, construcciones, conjuntos, sectores urbanos y demás objetos patrimoniales, que por su valor deben ser protegidos.

Para la comprensión y el entendimiento del tema de la valoración patrimonial, teniendo en cuenta los retos de la conservación armónica con el desarrollo integral de los pueblos, se hace necesario conocer conceptos, temáticas e instrumentos 
relacionados con el patrimonio construido, respecto a lo social, lo urbano y lo territorial, por una parte, y, por la otra en lo referente o relacionado con el manejo de los indicadores para las ciudades y los centros históricos, es así como se proponen las siguientes temáticas:

\section{El patrimonio cultural se define como el conjunto de bienes y mani- festaciones culturales materiales e inmateriales, que se encuentra en permanente construcción sobre el territorio transformado por las comunidades. Dichos bienes $y$ manifestaciones se constituyen en valores estimables que conforman sentidos y lazos de pertenencia, identidad y memoria para un grupo o colectivo humano (República de Colombia, Ministerio de Cultura 2005).}

La acción del hombre se inscribe en tres ámbitos que están estrechamente ligados con las dimensiones de tiempo y espacio: comunidad, territorio y memoria. El ser humano desarrolla su actividad en un espacio construido por él como territorio: extenso, abierto o reducido (donde incluye objetos y utensilios); de otra parte, con el paso del tiempo, va configurando y acumulando memoria
La confluencia de estos tres ámbitos define la cultura. Así pues, la cultura entendida como la manera en que una comunidad comprende su mundo, lo interpreta y lo maneja, tiene lugar dentro de un territorio y está sustentada en la memoria compartida por sus habitantes.

El patrimonio inmueble se caracteriza por estar fijo a la tierra, tal como las edificaciones, los conjuntos arquitectónicos, los asentamientos urbanos, las obras de ingeniería, los parques arqueológicos y las obras de adecuación del territorio para fines de explotación, producción o recreación. Las áreas cultivadas o explotadas, las obras de infraestructura y los ámbitos geográficos.

\section{Metodologia}

El inventario, la clasificación tipológica, la valoración y significación cultural de las edificaciones, son los elementos relevantes que soportan el instrumento que define el tipo de intervención (Integral, Arquitectónico y contextual) de acuerdo al nivel o estado de conservación de los inmuebles identificados como patrimoniales. Así mismo ayudan a establecer con claridad los indicadores de patrimonio en el área de los 
caños del Mercado Público, sector de Barranquillita en la ciudad de Barranquilla, que permitan una eficiente administración de los datos patrimoniales culturales e históricos del sector, y posibilite una efectiva toma de decisión hacia la conservación y crecimiento.

Para el desarrollo del proyecto se manejaron cuatro fases:

- Una primera fase relacionada con la Revisión y evaluación de la información existente; Revisión del Inventario cartográfico existente y la Revisión y Análisis de la información de las Bases de datos.

- La segunda fase relacionada con el inventario, la identificación y cuantificación de las edificaciones patrimoniales objeto del estudio (trabajo de campo); comprende el diligenciamiento de la matriz acompañadas del respectivo estudio fotográfico. Se anexan planos del orden conceptual (esquemas desarrollados a mano), de manera que se permita manejar la información a nivel de predio.

- El formato establecido para la matriz (Anexo No. 1), define lo relacionado con el análisis de la estructura urbana existente, y la valoración del contexto urbano construido; los valores ambiental, estético, simbólico y tecnológico del sitio. Con datos sobre: Emplazamiento (lote, sector); Ubicación (Departamento; Municipio; Barrio; Dirección; Datos del Lote o predio (frente, fondo, área); Sector; Manzana; Predio; Matrícula Inmobiliaria y Código catastral; Edad de la Construcción y Características arquitectónicas. Para las edificaciones con características y/o valores patrimoniales que se identifiquen, se establecerá un formato o ficha (Anexo No. 2 y No. $3)$, que definirá lo relacionado con el Emplazamiento; Características Compositivas de la edificación; la Disposición del lote (manzana completa, esquina o medianero); los números de pisos; Balcones y Esquema Compositivo (bipartito, tripartito, etc.).

- La tercera fase comprende el análisis para establecer los indicadores de patrimonio de los inmuebles patrimoniales en el sector de los caños del Mercado Público en la ciudad de Barranquilla.

- La cuarta fase comprende el dibujo de planos técnicos digitalizados por computadora, los cuales contienen la documentación gráfica del proyecto. 


\section{Resultados}

El Inventario de inmuebles Patrimoniales en el Sector de los Caños del Mercado Público (carrera 40 a carrera 46, entre calles 9 calle 10) de la ciudad de Barranquilla Distrito Especial, Industrial y Portuario, en su etapa inicial correspondiente a la visita al sitio del proyecto, muestra claramente el estado de deterioro ambiental del eco sistema y su entorno próximo, la influencia del mismo en la comunidad que lo cohabita, que sufre las incomodidades y la contaminación del afluente del caño del mercado por el vertimiento aguas servidas y desechos de todo tipo de materiales orgánicos, sin el control de las autoridades distritales.

Muchos son los aspectos que determinan el grado de inestabilidad y deterioro de la zona de Barranquillita. Respecto al Uso de la tierra, el entorno del caño del mercado público referente al estudio, está conformado por ocho (8) manzanas con edificaciones normalmente de un piso, destinadas al comercio de víveres, abarrotes y artículos de la canasta familiar, y otras adecuaciones tuguriales localizadas sobre los andenes y/o espacio público, e inclusive sobre las aceras público estacionario, que no permite la movilidad ni el flujo vehicular, ni mucho menos la libre circulación de los ciudadanos que realizan sus compras. El uso comercial del entorno del caño del mercado sólo se mezcla con usos industriales esporádicos (bodegas) que se entrelazan y el uso habitacional es nulo, lo cual genera el alto grado de inseguridad en la zona a partir de las cuatro o cinco de la tarde, momento en que cesan las compras.

La crisis de las Empresas Publicas encargadas del manejo del mercado llevó al deterioro de este edificio y su posterior demolición ampliando la actividad del mercado a las calles del centro. Hubo una falta de voluntad política para controlar a tiempo la invasión del espacio público, pues su negociación generaba inclusive dividendos electorales. La dimensión que ha tomado este problema es tan grande que cualquiera lo utiliza en su provecho personal; los propietarios del comercio formal expanden sus negocios sobre los andenes y este es el germen inicial del problema (negocio del espacio público). Es posible que los requerimientos establecidos en la Ley respecto a la faja paralela, a cada lado (ronda) de los cauces de los ríos, quebradas y arroyos, se cumpla físicamente de acuerdo al trazado vial 
y al paramento de las edificaciones del sector, pero la proliferación de cambuches, y construcciones tuguriales en banda continua a lo largo del caño del mercado, provee una situación que se torna aún más grave ante la falta de instrumentos y capacidad operativa del sector público para actuar en derecho. Las basuras y deshechos que son arrojados a diario, contaminan el caño del mercado; son una situación que refleja el grado de desconocimiento del problema por parte de las personas que ocupan el sector, es una cuestión de falta de educación que genera la incultura de "basuras al arroyo". En el registro fotográfico Se puede apreciar que en todos los sitios en donde los puentes atraviesan el caño del mercado, la gran cantidad de basuras es impresionante, sin selección de ningún tipo, que causa estancamiento del afluente y alta vulnerabilidad. (Anexos No. 11, 12, 13, 14, 15, 16, 17 y 18). Registro fotográfico.

La afluencia diaria de personas desplazadas, delincuentes, drogadictos, expendedores de drogas y dementes (desechables), muestran otra falencia del sector en lo relacionado a la falta de baños públicos en el sector del mercado, lo cual propicia que estas personas realicen sus necesidades en cualquier parte del cauce canalizado del caño, causando también la contaminación del afluente.

El espacio público de la estructura urbana de Barranquillita ha sufrido un deterioro progresivo y sistemático al nivel del sector, el barrio y la calle. Los estándares de diseño del sistema vial en zona, aunque generosos, por la época en que fueron trazados, se ven disminuidos progresivamente por la invasión del espacio público; los criterios de habitabilidad se redujeron al máximo también en forma sustancial; el sector de ciudad amable y a escala humana que se conformó en los inicios de su proceso urbano, ha dado paso a un entorno deshumanizado, segregado y en proceso de deterioro en cuanto a nivel de vida digna. En lo relacionado con las edificaciones correspondientes al análisis de patrimonio arquitectónico, aunque se presenta en forma inmediata ante ellas una maraña de elementos constructivos tuguriales, que dificultan el examen minucioso de cada una de estas, se define de inmediato una edificación con signos o características extraordinarias o excepcionales, y dos manzanas con construcciones de banda continua, con características tipológicas propias de la época. 


\section{El Inventario}

Para el desarrollo del Inventario, inicialmente se procedió a la revisión y evaluación de la información existente, la revisión de cartografía y el análisis de la información de las Bases de datos, de manera que sirvieran de apoyo al trabajo de campo. El trabajo de campo comprende el diligenciamiento de la matriz diseñada, con su respectivo estudio fotográfico y los planos o esquemas conceptuales desarrollados a mano, de manera que se permita manejar la información a nivel de manzanas, en grupos de dos (2) estudiantes de la Especialización en Restauración y Conservación del Patrimonio Arquitectónico de la Institución, Universidad de la Costa, CUC, previamente entrenados en la tarea.

En el desarrollo de la matriz para el inventario del sector se tuvieron en cuenta los elementos estructurante del sistema ambiental y paisajístico, compuesto por los elementos físicos naturales que definen la forma y estructura urbana del sector. Forman parte del sistema estructurante ambiental los terrenos e inmuebles localizados en los suelos urbanos y de expansión urbana en el sector de Barranquillita; como también los elementos complementa- urbano: constituido por los elementos de ornato, amueblamiento, recreación, información y servicio, higiene, seguridad, señalización y comunicación, los elementos vegetales y la arborización.

El formato establecido para la matriz (Anexo No. 1), define lo relacionado con el análisis de la estructura urbana existente, y la valoración del contexto urbano construido; los valores ambiental, estético, simbólico y tecnológico del sitio. Con datos sobre: Emplazamiento (lote, sector); Ubicación (Departamento; Municipio; Barrio; Dirección; Datos del Lote o predio (frente, fondo, área); Sector; Manzana; Predio; Matrícula Inmobiliaria y Código catastral; Edad de la Construcción y Características arquitectónicas.

\section{Detalles del Inventario por Manzanas}

\section{1. - Manzana 0321}

- Localidad: Norte Centro Histórico.

- Referencia Catastral: 0800101020321

- Dirección: Calle 9 y Calle 9B; Carrera $41 \mathrm{~N}$ y Carrera 41B

- Número de predios: 26 
- Referencia Catastral de Predios: 03210001; 03210002; 03210003; 03210004; 03210005; 03210006; 03210007; 03210008; 03210009; 03210010; 03210011; 032100012; 032100013; 032100014; 03210001; 032100015; 03210001; 032100017; 032100018; 032100019; 032100020; 032100021; 032100022; 032100023; 032100024; 032100025 y 032100026

- Área de la Manzana: 3.735.05 M2. $=100 \%$

- Área Ocupación de Predios: 2.582.74 M2. = $69.14 \%$

- Área Espacio Público: 248.64 M2. $=6.66 \%$

- Número de Pisos de las Edificaciones: Un (1) piso.

\section{2. - Manzana 0322}

- Localidad: Norte Centro Histórico.

- Referencia Catastral: 0800101020322

- Dirección: Calle 10 y calle 9, con carrera 41B y 42D

- Número de predios: 51
- Referencia Catastral de Predios: Ver tabla. Anexo No.24

- Área de la Manzana: 20.993.35 M2. $=100 \%$

- Área Ocupación de Predios: $15.158 .43 \mathrm{M} 2 .=72.20 \%$

- Área Espacio Público: 5.916.25 M2. $=28.18 \%$

- Número de Pisos de las Edificaciones: 5 Edificaciones de dos (2) pisos y 46 edificaciones de un (1) piso.

\section{3. - Manzana 0323}

- Localidad: Norte Centro Histórico.

- Referencia Catastral: 0800101020323

- Dirección: Localizada entre calle 9 y calle 10, y carrera 42D y carrera 43.

- Número de predios: 05

- Referencia Catastral de Predios: 001010203233001; 001010203233002 ; 001010203233003; 001010203233004 y 001010203233005.

- Área de la Manzana: 6.734.69 M2. $=100 \%$

- Área Ocupación de Predios: $5.608 .80 \mathrm{M} 2 .=83 \%$ 
- Área Espacio Público (andenes): 1.125.90 M2.

- Número de Pisos de las Edificaciones: Todas las edificaciones son de un (1) piso.

\section{4. - Manzana 0324}

- Localidad: Norte Centro Histórico.

- Referencia Catastral: 0800101020324

- Dirección: Calle 9 y calle 10; carrera 43 y carrera 43B

- Número de predios: 14

- Referencia Catastral de Predios:

- Área de la Manzana: 8.159.65 M2. $=100 \%$

- Área Ocupación de Predios: 7.178.10 M2. = $87.9 \%$

- Área Espacio Público: M2.

- Número de Pisos de las Edificaciones: Un (1) piso.

\section{5. - Manzana 0325}

- Localidad: Norte Centro Histórico.

- Referencia Catastral: 080010102325
- Número de predios: 34

- Referencia Catastral de Predios: Anexo No.

- Área de la Manzana: 4.178.36 M2. $=100 \%$

- Área Ocupación de Predios: 4.079.95 M2. = $97.6 \%$

- Área Espacio Público: 103.39 M2.

- Número de Pisos de las Edificaciones: Uno (1)

\section{6. - Manzana 0326}

- Localidad: Norte Centro Histórico

- Referencia Catastral: 0800101020326

- Dirección: Calle 9A y Calle 10; Carrera 44 y Carrera 45

- Número de predios: 31

- Referencia Catastral de Predios: ( Anexo No. 26)

- Área de la Manzana: 6.329.43 M2. $=100 \%$

- Área Ocupación de Predios: $4.456 \mathrm{M} 2 .=70.4 \%$

- Área Espacio Público: 561.90 M2.

- Número de Pisos de las Edificaciones: Uno (1) 


\section{7. - Manzana 0327}

- Localidad: Norte Centro Histórico.

- Referencia Catastral: 0800101020327

- Dirección: Calle 9C y calle 9B; carrera $41 \mathrm{~N}$ y carrera $41 \mathrm{~B}$

- Número de predios: Dos (2).

- Referencia Catastral Predios: 08001010203270001 ; 08001010203270901

- Área de la Manzana: 2.460 .13 M2. $=100 \%$

- Área Ocupación de Predios: 1.856.07 M2. $=75.45 \%$

- Área Espacio Público (andenes): 266,74 M2. = $10.85 \%$

- Número de Pisos de las Edificaciones: Un (1) piso.

- Observación: La manzana disponía originalmente de un patio libre central con un área de 337.31 M2. Actualmente invadida o sellada con techo.

\section{8. - Manzana 0328}

- Localidad: Norte Centro Histórico.

- Referencia Catastral: 0800101020328
- Dirección: Calle 9C y calle 10; Carrera 41 y $41 \mathrm{~B}$

- Número de predios: 5

- Referencia Catastral de Predios: 0328001; 0328002; 0328003; 0328004 y 0328005.

- Área de la Manzana: 1.881 .19 M2. $=100 \%$

- Área Ocupación de Predios: 1.593.45 M2. = $84.7 \%$

- Área Espacio Público: 287.92 M2. $=15.3 \%$

- Número de Pisos de las Edificaciones: Una (1) edificación de 2 pisos (0328002); las cuatro restantes de 1 piso.

\section{Criterios de valoración}

\section{Contexto Ambiental:}

El entorno de la manzana, se encuentra habitada por vendedores ambulantes, recicladores y drogadictos entre otros, personas que permanecen durante el día en el sector y que no tienen sentido de pertenencia por su hábitat. Desarrollan todo tipo de actividades y necesidades fisiológicas en cualquier lugar, produciendo deterioro físico, ambiental y visual. 
De igual forma, generan una alto índice de inseguridad, a todos aquellos usuarios que llegan a realizar actividades de comercio en el sector. Las consideraciones generales relacionadas con lo ambiental en el diagnóstico de la manzana son los siguientes:

- Contaminación visual causada por: Señalización de tipo comercial sin reglamentaciones de tamaño, ni ubicación; Redes aéreas de distribución de servicios eléctricos y de telefonía en avanzado estado de deterioro y desorganización; manejo inapropiado de residuos generados por transeúntes y vendedores estacionarios, en especial los perecederos, y de los indigentes, causando malos olores y condiciones de insalubridad en general; Emisión de gases contaminantes que produce el parque automotor en especial de buses y camiones; hacinamiento y deterioro de los puestos de venta estacionarias que ocupan el espacio público;

- Contaminación por ruido, causados por: Congestiones de tráfico vehicular; actividad de promoción comercial; música a alto volumen en ventas de cervezas $y$ refrescos.

\section{Patología General:}

Las manzanas presentan una morfología rectangular, ligeramente angosta sobre las carreras, se desarrollan más hacia lo largo de las calles. Las manzanas presentan oficialmente una división predial, aunque en la práctica el inmueble es una sola edificación que abarca toda la manzana y que poseían originalmente una tipología de patio central. Son completamente nulas en cuanto a vegetación se refiere ya que no manejan ningún tipo de arborización en andenes, y en las fotografías aéreas se aprecia que el patio central está invadido, por lo cual el patio no posee tampoco vegetación. Dado el tipo de edificaciones, podría decirse que las manzanas son completamente herméticas. Las edificaciones manejan un concepto de espacios de actividad comercial continuada, uno tras otro, por todas sus fachadas. Las edificaciones, a juzgar por el hecho en que se evidencia la falta de mantenimiento, no amenazan ruina.

El análisis de las manzanas muestra un terreno que a pesar de estar alrededor del caño con alto nivel freático por su cercanía al Rio Magdalena, no genera riesgo de inundaciones. Se ha generado a través de los años un gran deterioro en las estructuras de las edificaciones. 
Además de esto se observaron las siguientes patologías.

- Andenes en un alto grado de deterioro.

- Se observan aleros agregados a las edificaciones con pie-amigos en madera y zinc en mal estado, que son un riesgo para los transeúntes y habitantes del sector.

- Gran parte de las tejas de cubierta, se encuentran en mal estado, despegadas poniendo en riesgo a los transeúntes.

- La humedad y falta de mantenimiento de las edificaciones de la manzana, ha ocasionado deterioro en los muros de fachada.

- La ausencia de pañete en algunos sectores de los muros de las fachadas, sumado a la humedad existente en el sector, ha generado un deterioro evidente en la caja muraria.

- Intervenciones inadecuadas, posibles causantes de cantidad de fisuras internas de los muros.

- La patología que presentan las edificaciones de las manzanas muestran diversos tipo de deterioro, como humedades; rotura y desprendimiento de pañetes en las fachadas; deterioro de los andenes (demoliciones y agrietamientos); vías deterioradas por tramos, con pozos de aguas estancadas y malolientes.
Entorno Circundante:

El entorno del estudio se encuentra ubicado en el emplazamiento donde históricamente, se señala como sitio fundacional o de poblamiento inicial de Barranquilla. Su cercanía inmediata con el Caño del Mercado, que una vez le represento el surgimiento al sector mediante una dinámica comercial, hoy le cercena; el Caño se encuentra con una preocupante problemática ambiental, surgido entre otras por el desvió de su curso inicial y la reducción del ancho original, cuenta éste con un cerramiento en muro a baja altura y malla, con la intención inicial que las personas no puedan arrojar basuras a este. Las calles que le rodean por sus otras fachadas se encuentran en mal estado, los andenes en algunos tramos son inexistentes y no cuenta con arborización. La única presencia vegetal rodea el borde del Caño.

El entorno muestra deficiencias, al encontrase invadido por las ventas estacionarias, tanto en vías como en los andenes; alto grado de contaminación auditiva por flujo vehicular; la inseguridad para los peatones y compradores generada por delincuentes, viciosos y dementes; edificaciones abandonadas; contaminación del caño del mercado por basuras y residuos orgánicos y perecederos. 


\section{Análisis Dofa del Sector}

\begin{tabular}{|c|c|}
\hline \multicolumn{2}{|r|}{ UNIVERSIDAD DE LACOSTA, CUC } \\
\hline \multicolumn{2}{|r|}{ FACULTAD DE ARQUITECTURA DEPARTAMENTO DE POSGRADOS } \\
\hline \multicolumn{2}{|r|}{ ESPECIALIZACION EN RESTAURACION Y CONSERVACION DEL PATRIMONIO ARQUITECTONICO } \\
\hline \multicolumn{2}{|r|}{ INVENTARIO DE INMUEBLES PATRIMONIALES } \\
\hline \multicolumn{2}{|r|}{ MATRIZ DOFA } \\
\hline GRUPO 1. & MANZANA 328 \\
\hline \multirow{3}{*}{ FORTALEZAS } & 1.La manzana 325 se encuentra ubicada cerca al caño de las ahuyama. \\
\hline & 2. La velocidad del viento predomina hacia la manzana. \\
\hline & 3. Las vias se encuentran en estado aceptable con relación a todo el sector. \\
\hline
\end{tabular}

\begin{tabular}{l|l} 
DEBILIDADES. & 1.Tanto la manzana como el sector se encuentra invadido el espacio publico \\
\cline { 2 - 2 } & 2. Contan
\end{tabular}

2. Contaminación del Caño de la Ahuyama

\begin{tabular}{|l|l|l|}
\hline OPORTUNIDADES. & 1. El sector emerge el desarrollo comercial, cultural, y turistico para la ciudad de Barranquilla \\
\hline
\end{tabular}

\begin{tabular}{|c|l|}
\hline AMENAZAS & 1. Degradación ambiental a nivel de contaminación atmosferica y visual \\
\hline & \\
\hline \multirow{2}{*}{ OPORTUNIDADES. } & 1. Planes de renovación urbana en el sector \\
\cline { 2 - 2 } & 2. Excelente ubicación junto al caño del mercado \\
\cline { 2 - 2 } & 3. Posibilidad de inclusión en el Plan Parcial de Barranquillita \\
\hline
\end{tabular}

\begin{tabular}{|l|l|}
\hline \multirow{2}{*}{ AMENAZAS } & 1.Zona inundable por el caño \\
\cline { 2 - 2 } & 2. Perdida de la dinamica comercial por nuevos sectores. \\
\hline GRUPO 3. & MANZANA 321 \\
\hline \multirow{3}{*}{ FORTALEZAS } & 1. Actividad Economica en el sector \\
\cline { 2 - 2 } & 2. Nuevo Portal de Transmetro \\
\cline { 2 - 2 } & 3. Futuros proyectos de renovación Urbana \\
\cline { 2 - 2 } & 4. Conserva su plaza inicial interna como plaza de parqueo \\
\hline
\end{tabular}

\begin{tabular}{|l|l|}
\hline \multirow{3}{*}{ DEBILIDADES. } & 1. Ventas estacionarias y ambulantes \\
\cline { 2 - 2 } & 2. Deterioro ambiental (basuras) \\
\cline { 2 - 2 } & 3. Inseguridad \\
\cline { 2 - 2 } & 4.Falta de vegetación. \\
\hline
\end{tabular}

\begin{tabular}{|l|l|}
\hline \multirow{3}{*}{ OPORTUNIDADES. } & 1. Proyecto de Desarrollo Vial \\
\cline { 2 - 2 } & 2. Saneamiento de los caños \\
\cline { 2 - 2 } & 3. Renovación Urbana del Centro de Barranquilla \\
\cline { 2 - 2 } & 4. Futura Plaza Ujueta. \\
\hline
\end{tabular}

\begin{tabular}{|l|l|}
\hline \multirow{4}{*}{ AMENAZAS } & 1. Inseguridad \\
\cline { 2 - 2 } & 2. Falta de Autoridad y control \\
\cline { 2 - 2 } & 3. Invasión del espacio publico \\
\cline { 2 - 2 } & 4. Deterioro ambiental e insalubridad \\
\cline { 2 - 2 } & 5. Deterioro fisico y visual \\
\hline \multirow{2}{*}{ GRUPO 4 } & MANZANA 325 \\
\hline \multirow{2}{*}{ FORTALEZAS } & 1.La manzana 325se encuentra ubicada cerca al caño de las a huyama. \\
\cline { 2 - 2 } & 2. La velocidad del viento predomina hacia la manzana. \\
\cline { 2 - 2 } & 3. Las vias se encuentran en estado aceptable con relación a todo el sector. \\
\hline
\end{tabular}

\begin{tabular}{l|l}
\hline \multirow{2}{*}{ DEBILIDADES. } & 1.Tanto la manzana como el sector se encuentra invadido el espacio publico \\
\cline { 2 - 2 } & 2. Contaminacion de Cano dela
\end{tabular}

DEBILIDADES. $\quad$ 2. Contaminación del Caño de la Ahuyama

\begin{tabular}{|l|l|l|l}
\hline OPORTUNIDADES. & 1. El sector emerge el desarrollo comercial, cultural, y turistico para la ciudad de Barranquilla \\
\hline
\end{tabular} 


\begin{tabular}{|c|c|}
\hline GRUPO 5. & MANZANA 323 \\
\hline \multirow{3}{*}{ FORTALEZAS } & 1. Actividad economica en el sector \\
\hline & 1. Zona de alto uso comercial. \\
\hline & 3. Vias conectoras con la ciudad \\
\hline \multirow{6}{*}{ DEBILIDADES. } & 1. Invasión del espacio publico \\
\hline & 2. Inseguridad en el sector \\
\hline & 3. Deficiencia Ambiental \\
\hline & 4. Deficiencia de zonas para parques \\
\hline & 5. Contaminación ambiental \\
\hline & 6. Alto deterioro de las edificaciones \\
\hline \multirow{3}{*}{ OPORTUNIDADES. } & 1. Conectividad vial \\
\hline & 2. Punto es trategico cerca al Rio Magdalena \\
\hline & 3. Proyecto Corredor Portuario \\
\hline \multirow{3}{*}{ AMENAZAS } & 1. Alta inseguridad \\
\hline & 2. Contaminación ambiental. \\
\hline & 3. ventas ambulantes y estacionarias en los andenes. \\
\hline GRUPO 6. & MANZANA 324 \\
\hline \multirow{3}{*}{ FORTALEZAS } & 1. Vias que comunican con la ciudad \\
\hline & 2. Alto nivel comercial \\
\hline & 3. Zona de Renovación Urbana \\
\hline \multirow{2}{*}{ DEBILIDADES. } & 1. Alto nivel de invasión del Espacio Publico \\
\hline & 2. Falta de zonas de parques \\
\hline \multirow{2}{*}{ OPORTUNIDADES. } & 1. Edificaciones en buen estado \\
\hline & 2. Buenos perfiles viales \\
\hline \multirow{2}{*}{ AMENAZAS } & 1. Alto nivel de contaminación ambiental \\
\hline & 2. Alto nivel de inseguridad en el sector \\
\hline GRUPO 7. & MANZANA 322 \\
\hline \multirow{3}{*}{ FORTALEZAS } & 1. La manzana posee grandes espacios publicos \\
\hline & 2. Vias en estado aceptable \\
\hline & 3. Frecuencia de vientos provenientes del rio \\
\hline \multirow{2}{*}{ DEBILIDADES. } & 1. Se encuentra totalmente invadido por vendedores que se establecieron en el sitio \\
\hline & 2. Fuertes olores que llegan des de el contaminado Caño de la Ahuyama hacia el sector \\
\hline \multirow{2}{*}{ OPORTUNIDADES. } & 2. Se encuentra un sector de grandes potencialidades turisticas \\
\hline & 2. Es un sitio muy frecuentado por los ciudadanos \\
\hline \multirow{3}{*}{ AMENAZAS } & 1. la fuerte contaminación del lugar. \\
\hline & 2. Venta de drogas \\
\hline & 3. Olvido estatal \\
\hline \multicolumn{2}{|r|}{ UNIVERSIDAD DE LACOSTA, CUC } \\
\hline \multicolumn{2}{|r|}{ FACULTAD DE ARQUITECTURA DEPARTAMENTO DE POSGRADOS } \\
\hline \multicolumn{2}{|r|}{ ESPECIALIZACION EN RESTAURACION Y CONSERVACION DEL PATRIMONIO ARQUITECTONICO } \\
\hline \multicolumn{2}{|r|}{ INVENTARIO DE INMUEBLES PATRIMONIALES } \\
\hline & MATRIZ DOFA \\
\hline
\end{tabular}




\section{Los Indicadores}

Esta fase describe el proceso de construcción de indicadores que podrían implementarse en la gestión del plan de rehabilitación del sector de Barranquillita, anexo al centro histórico de la ciudad de Barranquilla. Se hace un acercamiento a los procesos de selección, definición y clasificación de los indicadores, tanto cualitativos como cuantitativos. De acuerdo con este sistema, se analizaron y estudiaron los indicadores relacionados para el monitoreo del plan, enfocados en la conservación y la intervención física del espacio urbano, como una forma para mejorar su calidad y de preservar el patrimonio arquitectónico. De todas maneras se señalan sus limitaciones y perspectivas. La construcción y manejo del método o sistema de trabajo para el desarrollo y la definición de indicadores fueron un reto. Ahora, la idea es continuar el proceso, que exige nuevas medidas, capaces de articular los recursos políticos, administrativos y técnicos, asegurando la implementación de este instrumento en el área total del sector Barranquillita.

Con el monitoreo a través de los indicadores, se pretende proveer una visión del programa de rehabilitación física, el uso y mejoramiento del espacio público, sobre el inventario, y los activos del patrimonio; como continuación a otras acciones establecidas en el PEMP (Plan Especial de Manejo y Protección) del Centro Histórico del Distrito de Barranquilla, hacia Barranquillita. Además se requiere una dinámica integrada, que califique la gestión urbana y la conservación del patrimonio inmueble, así como la promoción del desarrollo económico y turístico de todo el Sector.

La falta de literatura especializada, en algunos casos hizo necesario plantear unos indicadores, diseñados sobre la base del objetivo de la evaluación a partir de referencias bibliográficas específicas. La complejidad y articulación de los factores identificados con los criterios generalmente aceptados para los sistemas de indicadores (OECD, 1994), permite proceder en primer lugar, identificando todos los indicadores necesarios para evaluar cada factor; y posteriormente, establecer unos criterios de priorización, organización y selección de los indicadores para su utilización, como por ejemplo: Que estén relacionados con objetivos claros de planificación; Que midan aspectos modificables, es decir, sobre los que se pueda actuar directamente mediante planificación; y que sean comprensibles por la población. El procedimiento metodológico está basado en los instrumentos adoptados por los sistemas mundiales de gestión del patrimonio natural y cultural. 


\section{Valor del contexto urbano construido}

\begin{tabular}{|c|}
\hline UNIVERSIDAD DE LACOSTA, CUC \\
\hline FACULTAD DE ARQUITECTURA DEPARTAMENTO DE POSGRADOS \\
\hline ESPECIALIZACION EN RESTAURACION Y CONSERVACION DEL PATRIMONIO ARQUITECTONICO \\
\hline INVENTARIO DE INMUEBLES PATRIMONIALES SECTOR CAÑOS DEL MERCADO PUBLICO - TABULACIÓN \\
\hline
\end{tabular}

Evalue: (1)= insostenible; (2)= deficiente; (3)= aceptable; (4)= satisfactorio; (5)= eficiente; (6)= óptimo

\begin{tabular}{|c|c|c|c|c|c|c|c|c|c|c|}
\hline \multicolumn{9}{|c|}{ 1. - VALOR DEL CONTEXTO URBANO CONSTRUIDO. } & \multirow{2}{*}{$\begin{array}{c}\text { PROMEDIO } \\
\text { REDONDEADO }\end{array}$} & \multirow{2}{*}{\begin{tabular}{|l} 
\\
PROMEDIO EXACTO
\end{tabular}} \\
\hline COMPONENTES & Mz 0328 & Mz 0327 & Mz 0321 & Mz 0325 & Mz 0323 & Mz 0324 & Mz 0322 & Mz 0326 & & \\
\hline Cesiones de manzana. & 2 & 2 & 2 & 3 & 3 & 1 & 2 & 3 & 2 & 2,3 \\
\hline Continuidad del trazado. & 3 & 4 & 4 & 3 & 4 & 4 & 2 & 3 & 3 & 3,4 \\
\hline Morfologia urbana. & 2 & 4 & 4 & 2 & 5 & 4 & 3 & 3 & 3 & 3,4 \\
\hline Tipología Edificatoria. & 3 & 3 & 3 & 2 & 5 & 4 & 2 & 0 & 3 & 2,8 \\
\hline Division Predial. & 2 & 1 & 2 & 2 & 3 & 3 & 2 & 4 & 2 & 2,4 \\
\hline Densidad de Ocupación. & 1 & 1 & 4 & 4 & 2 & 1 & 1 & 3 & 2 & 2,1 \\
\hline Imagen Urbana. & 1 & 1 & 1 & 2 & 2 & 2 & 2 & 2 & 2 & 1,6 \\
\hline Perfiles viales. & 3 & 5 & 4 & 3 & 4 & 4 & 4 & 3 & 4 & 3,8 \\
\hline Empalmes volumetricos & 3 & 4 & 3 & 2 & 2 & 4 & 1 & 0 & 2 & 2,4 \\
\hline Paramentos de Manzana. & 2 & 5 & 4 & 3 & 4 & 3 & 3 & 3 & 3 & 3,4 \\
\hline
\end{tabular}

\section{1. - VALOR DEL CONTEXTO URBANO CONSTRUIDO.}

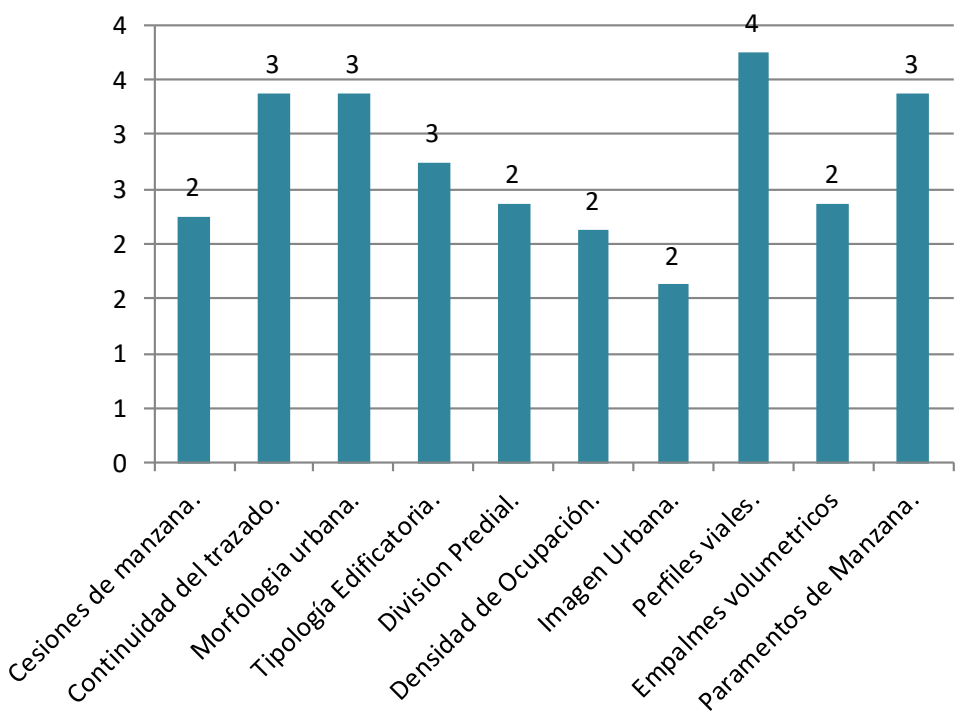

1. - VALOR DEL CONTEXTO URBANO CONSTRUIDO. 


\section{Valor urbano del sitio}

UNIVERSIDAD DE LACOSTA, CUC

FACULTAD DE ARQUITECTURA DEPARTAMENTO DE POSGRADOS

ESPECIALIZACION EN RESTAURACION Y CONSERVACION DEL PATRIMONIO ARQUITECTONICO

INVENTARIO DE INMUEBLES PATRIMONIALES SECTOR CAÑOS DEL MERCADO PUBLICO - TABULACIÓN

Evalue: (1)= insostenible; (2)= deficiente; (3)= aceptable; (4)= satisfactorio; (5)= eficiente; (6)= óptimo

\begin{tabular}{|c|c|c|c|c|c|c|c|c|c|c|}
\hline \multicolumn{10}{|c|}{ 2. - VALOR AMBIENTAL URBANO DEL SITIO } & \multirow[b]{2}{*}{ PROMEDIO EXACTO } \\
\hline COMPONENTES & Mz 0328 & Mz 0327 & Mz 0321 & Mz 0325 & Mz 0323 & Mz 0324 & Mz 0322 & Mz 0326 & PROMEDIO & \\
\hline Radiacion Solar & 2 & 5 & 0 & 3 & 6 & 6 & 3 & 6 & 4 & 3,9 \\
\hline Vegetacion & 1 & 1 & 1 & 1 & 3 & 1 & 1 & 3 & 2 & 1,5 \\
\hline Paisaje & 1 & 1 & 1 & 1 & 2 & 2 & 1 & 2 & 1 & 1,4 \\
\hline Atmosfera & 1 & 1 & 1 & 3 & 2 & 1 & 1 & 2 & 2 & 1,5 \\
\hline HaBitat & 1 & 1 & 1 & 2 & 1 & 1 & 1 & 3 & 1 & 1,4 \\
\hline Asoleamiento & 2 & 5 & 6 & 6 & 6 & 6 & 6 & 6 & 5 & 5,4 \\
\hline Temperatura & 2 & 2 & 3 & 3 & 2 & 2 & 3 & 2 & 2 & 2,4 \\
\hline Vientos & 3 & 2 & 2 & 4 & 3 & 4 & 3 & 2 & 3 & 2,9 \\
\hline Confort & 1 & 1 & 1 & 1 & 1 & 1 & 1 & 1 & 1 & 1,0 \\
\hline Cobertura Vegeta & 1 & 1 & 1 & 1 & 1 & 1 & 1 & 3 & 1 & 1,3 \\
\hline
\end{tabular}

\section{2. - VALOR AMBIENTAL URBANO DEL SITIO}

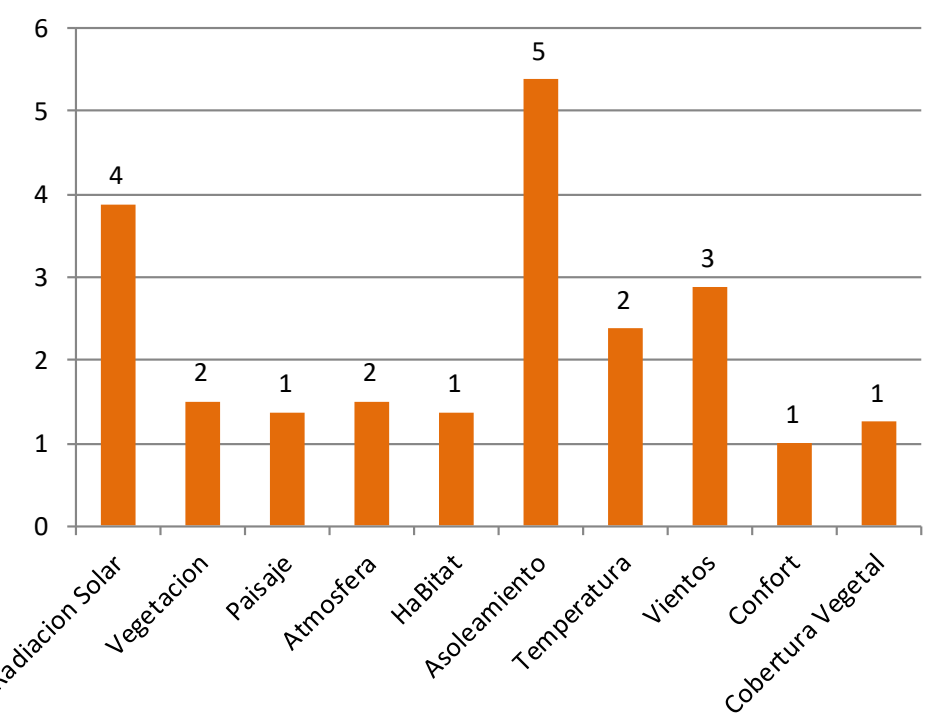

2. - VALOR AMBIENTAL URBANO DEL SITIO 


\section{Valor Estético Urbano del Sitio}

UNIVERSIDAD DE LACOSTA, CUC

FACULTAD DE ARQUITECTURA DEPARTAMENTO DE POSGRADOS

ESPECIALIZACION EN RESTAURACION Y CONSERVACION DEL PATRIMONIO ARQUITECTONICO

INVENTARIO DE INMUEBLES PATRIMONIALES SECTOR CAÑOS DEL MERCADO PUBLICO - TABULACIÓN

Evalue: $(1)=$ insostenible; $(2)=$ deficiente; $(3)=$ aceptable; $(4)=$ satisfactorio; $(5)=$ eficiente; $(6)=$ óptimo

\section{3. - VALOR ESTETICO URBANO DEL SITIO}

\begin{tabular}{|c|c|c|c|c|c|c|c|c|c|c|}
\hline \multicolumn{10}{|c|}{ 3. - VALOR ESTETICO URBANO DEL SITIO } & \multirow[b]{2}{*}{\begin{tabular}{|l} 
PROMEDIO EXACTC \\
\end{tabular}} \\
\hline \begin{tabular}{|l|} 
COMPONENTES \\
\end{tabular} & Mz 0328 & Mz 0327 & Mz 0321 & Mz 0325 & Mz 0323 & Mz 0324 & Mz 0322 & Mz 0326 & PROMEDIO & \\
\hline Tipologias Arquitectonicas & 3 & 3 & 3 & 2 & 3 & 2 & 2 & 4 & 3 & 2,8 \\
\hline Composición y Orden & 2 & 3 & 2 & 3 & 3 & 0 & 1 & 2 & 2 & 2,0 \\
\hline Espacialidad & 2 & 2 & 2 & 2 & 1 & 1 & 1 & 2 & 2 & 1,6 \\
\hline Funcionalidad & 1 & 2 & 3 & 2 & 3 & 3 & 1 & 1 & 2 & 2,0 \\
\hline Eficiencia & 1 & 1 & 2 & 2 & 3 & 1 & 1 & 1 & 2 & 1,5 \\
\hline Estructura & 2 & 3 & 2 & 3 & 4 & 4 & 2 & 3 & 3 & 2,9 \\
\hline \begin{tabular}{|l} 
Lenguaje y Estilo \\
\end{tabular} & 2 & 3 & 3 & 2 & 3 & 3 & 1 & 2 & 2 & 2,4 \\
\hline Circulacion y Recorrido & 1 & 1 & 2 & 1 & 1 & 1 & 3 & 1 & 1 & 1,4 \\
\hline Estancia y Permanencia & 1 & 1 & 1 & 1 & 2 & 2 & 1 & 3 & 2 & 1,5 \\
\hline Ornamento Decorativo & 4 & 3 & 1 & 1 & 1 & 1 & 1 & 1 & 2 & 1,6 \\
\hline \begin{tabular}{|l|} 
Fachadas \\
\end{tabular} & 3 & 3 & 2 & 2 & 4 & 4 & 2 & 3 & 3 & 2,9 \\
\hline Elementos Arquitectonicos & 4 & 4 & 1 & 1 & 1 & 2 & 1 & 1 & 2 & 1,9 \\
\hline Material & 3 & 3 & 3 & 2 & 5 & 5 & 1 & 5 & 3 & 3,4 \\
\hline Edificios Significativos & 6 & 1 & 2 & 1 & 1 & 1 & 1 & 1 & 2 & 1,8 \\
\hline Perfil Urbano & 3 & 2 & 4 & 2 & 3 & 3 & 3 & 3 & 3 & 2,9 \\
\hline
\end{tabular}

\section{3. - VALOR ESTETICO URBANO DEL SITIO}

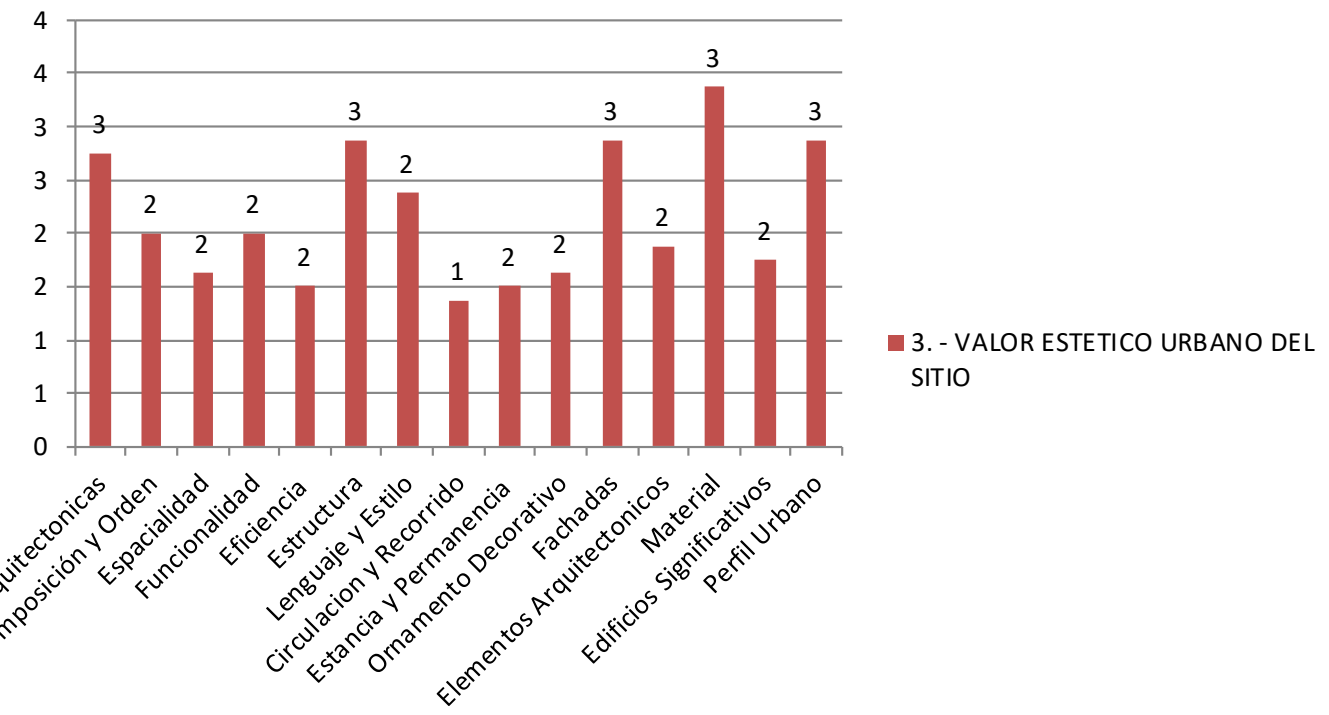




\section{Valor simbólico urbano del sitio}

UNIVERSIDAD DE LACOSTA, CUC

FACULTAD DE ARQUITECTURA DEPARTAMENTO DE POSGRADOS

ESPECIALIZACION EN RESTAURACION Y CONSERVACION DEL PATRIMONIO ARQUITECTONICO

INVENTARIO DE INMUEBLES PATRIMONIALES SECTOR CAÑOS DEL MERCADO PUBLICO - TABULACIÓN

Evalue: $(1)=$ insostenible; $(2)=$ deficiente; $(3)=$ aceptable; $(4)=$ satisfactorio; $(5)=$ eficiente; $(6)=$ óptimo

\begin{tabular}{|c|c|c|c|c|c|c|c|c|c|c|}
\hline \multicolumn{10}{|c|}{ 4. - VALOR SIMBOLICO URBANO DEL SITIO } & \multirow[b]{2}{*}{ PROMEDIO EXACTO } \\
\hline COMPONENTE & \begin{tabular}{|l|} 
Mz 0328 \\
\end{tabular} & Mz 0327 & Mz 0321 & Mz 0325 & Mz 0323 & Mz 0324 & Mz 0322 & Mz 0326 & PROMEDIO & \\
\hline Significado Social & 1 & 1 & 1 & 2 & 2 & 2 & 3 & 2 & 2 & 1,8 \\
\hline Memoria Historica & 6 & 5 & 5 & 4 & 4 & 4 & 2 & 2 & 4 & 4,0 \\
\hline Escenario Turistico & 1 & 1 & 1 & 1 & 1 & 1 & 1 & 2 & 1 & 1,1 \\
\hline Imaginario Cultural & 4 & 1 & 1 & 2 & 1 & 1 & 2 & 1 & 2 & 1,6 \\
\hline
\end{tabular}

\section{4. - VALOR SIMBOLICO URBANO DEL SITIO}

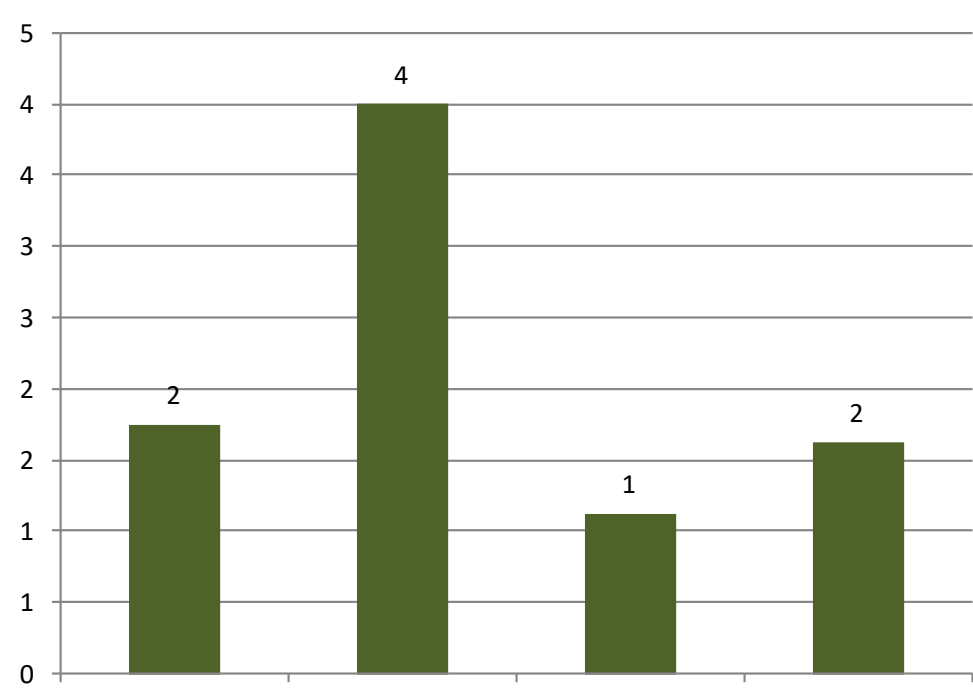

4. - VALOR SIMBOLICO URBANO DEL SITIO

Significado Social Memoria Historica Escenario Turistico Imaginario Cultura 


\section{Valor tecnológico urbano del sitio}

UNIVERSIDAD DE LACOSTA, CUC

FACULTAD DE ARQUITECTURA DEPARTAMENTO DE POSGRADOS

ESPECIALIZACION EN RESTAURACION Y CONSERVACION DEL PATRIMONIO ARQUITECTONICO

INVENTARIO DE INMUEBLES PATRIMONIALES SECTOR CAÑOS DEL MERCADO PUBLICO - TABULACIÓN

Evalue: (1)= insostenible; (2)= deficiente; (3)= aceptable; (4)= satisfactorio; (5)= eficiente; (6)= óptimo

\begin{tabular}{|c|c|c|c|c|c|c|c|c|c|c|}
\hline \multicolumn{10}{|c|}{ 5. - VALOR TECNOLOGICO URBANO DEL SITIO } & \multirow[b]{2}{*}{ PROMEDIO EXACTO } \\
\hline COMPONENTE & Mz 0328 & Mz 0327 & Mz 0321 & Mz 0325 & Mz 0323 & Mz 0324 & Mz 0322 & $\mathrm{Mz} 0326$ & PROMEDIO & \\
\hline Conservacion Estructural & 2 & 3 & 3 & 2 & 3 & 1 & 2 & 5 & 3 & 2,6 \\
\hline Manejo Bioclimatico & 1 & 1 & 1 & 1 & 2 & 1 & 1 & 2 & 1 & 1,3 \\
\hline Flexibilidad & 1 & 1 & 1 & 3 & 1 & 1 & 2 & 3 & 2 & 1,6 \\
\hline Vias & 2 & 2 & 2 & 2 & 4 & 4 & 3 & 3 & 3 & 2,8 \\
\hline Equipamiento & 1 & 1 & 1 & 1 & 2 & 1 & 1 & 2 & 1 & 1,3 \\
\hline
\end{tabular}

\section{5. - VALOR TECNOLOGICO URBANO DEL SITIO}

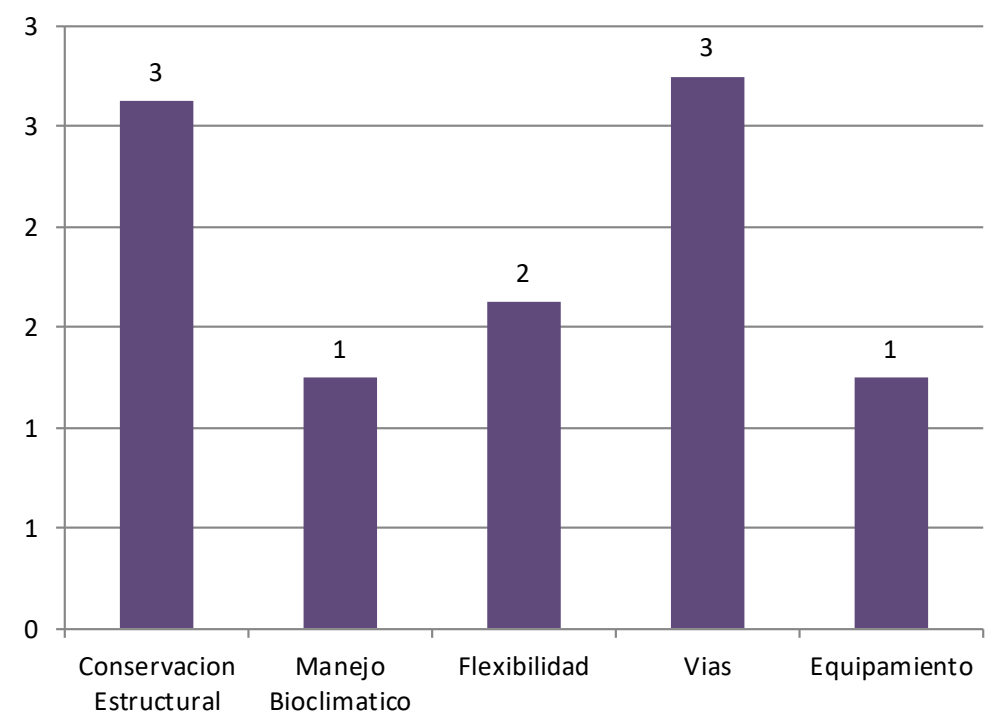

5.-VALOR TECNOLOGICO URBANO DEL SITIO 


\section{Discusión}

La elaboración de Inventarios de patrimonio, muestra la importancia que para una sociedad tiene el identificar y proteger sus bienes de interés cultural. Estos inventarios implican procedimientos valorativos que buscan no solo identificar sino comprender, jerarquizar, clasificar y evaluar de manera individualizada y en conjunto, aquellos bienes, construcciones, conjuntos, sectores urbanos y demás objetos patrimoniales, que por su valor deben ser protegidos. (Tello, 2008)

Se debe tener cuidado en la adaptación funcional del patrimonio urbano a las exigencias de calidad de vida actuales, es decir, la transformación continúa de la ciudad y/o de los centros históricos, permite el cambio en el entorno construido de interés patrimonial, para lo cual se hace necesario tener un conocimiento del objeto de estudio, que tenga en cuenta técnicas constructivas, tipologías distributivas, tipologías edificatorias y de la trama urbana. El Reto está en modificar sin destruir.

Incentivar políticas que contribuyan con el mejoramiento del planeamiento de las intervenciones que se realizan alrededor y al interior de los bienes inmuebles patrimoniales ubicados en la ciudad de Barranquilla, su Centro Histórico y el Sector de Barranquillita, buscando la valoración de los predios patrimoniales. Teniendo en cuenta las amplias formulaciones referentes al "impacto de las actividades económicas sobre el patrimonio cultural: empleo, turismo, capacitación, comercialización, modos de producción, entre otros y calidad de vida: educación, salud trabajo, alimentación, vivienda y otros".

\section{Implementar la "diversidad de} usos del patrimonio histórico urbano". La desaparición de diversidad funcional en los centros históricos es una de las principales amenazas para su conservación (Martínez, 2001) y es un factor que suele estar relacionado con el abandono de los residentes. De hecho, los primeros usos que habría que proteger son los servicios para residentes (Sarasa, 2005)), a menudo sacrificados por establecimientos turísticos o terciarios a escala ciudadana o regional.

Buscar Calidad en manejo y suministro de la información relacionada con los predios patrimoniales de la ciudad, garantizando confianza, eficiencia y economía en el manejo de los datos, generando a la vez faci- 
lidad para el correcto monitoreo de los inmuebles, frente a las diversas anomalías que se presentan al interior o en el entorno de los mismos. Evitar que las problemáticas existen tanto urbanas como socioeconómicas se conviertan en común denominador en nuestras ciudades creadas bajo planes de ordenamientos pre-históricos debido a que se hacen obsoletos frente a las transformaciones urbanas, tales como: la expansión urbana, el deseo de crecer como una metrópolis, la globalización, las distintas tecnologías que surgen y la pérdida de sus reservas ecológicas por la degradación producida a causa de la mano del hombre sobre el Medio Ambiente. (Romañas, Vidal y Rodriguez, 2014)

Luego de analizado el FODA del sector de Barranquillita, realizado en conjunto con los estudiantes de la Especialización en Restauración y Conservación del Patrimonio Arquitectónico de la Universidad de la Costa CUC, se recomienda para el mejoramiento del mismo, algunas actuaciones y estrategias:

Actuaciones para estructurar el Sistema de Espacio Público:
- Mantenimiento continuado del cauce (zona canalizada) del caño del mercado público, como elemento paisajístico que articula el sector de Barranquillita con el área del Centro Histórico.

- Generar corredores verdes paralelos a la ronda hídrica del caño del mercado público, es decir la arborización debe identificar lugares y paseos.

- Recuperación de zonas públicas, andenes y vías actualmente ocupadas y deterioradas.

Actuaciones para la recuperación ambiental: Saneamiento ambiental integral del cauce y la ronda hídrica del caño del mercado público.

Generación de espacio público, donde se pretende dar al habitante o transeúnte cotidiano o espontáneo zonas verdes de recreación pasiva y activa y otras de esparcimiento, y fomento a la cultura, entre otros. Para su implementación será necesaria la elaboración de un plan de acciones, en donde participen todas las empresas que funcionan en el sector, de tal forma que se planifiquen y coordinen las actividades para la ejecución de las obras. 
En el marco del Sistema Social Desarrollar una Propuesta de traslado de vendedores estacionarios.

- Plantear un programa de traslado de las personas ubicadas en la zona de la ronda del caño del mercado y ejercer un mayor control ambiental del mismo. Está propuesta sé deberá manejar de acuerdo con un plan con calidad urbana que mejore las calidad de vida de los residentes y visitantes.

- Mejorar las condiciones de vida de los actuales habitantes de la zona objeto de estudio, ordenando la infraestructura actual de vivienda y de apoyo social a la comunidad residente para que el sector no permanezca solo en horas de la noche.

- Dar una solución integral a la problemática de vivienda.

Como estrategias, se deberá elaborar un censo y diagnóstico socioeconómico, que permita identificar las condiciones económicas, sociales, culturales reales de la población a trasladar a otro centro de mercadeo dentro del mismo sector, y al mismo tiempo medir los impactos negativos.
- Controlar el proceso de ocupación de los sitios motivo del programa de traslado, incluyendo una definición de las familias beneficiarias del programa mediante inscripción formal y el establecimiento de mecanismos restrictivos de nuevas ocupaciones

- Establecer compromisos con la comunidad para que coadyuven a mejorar las condiciones de aseo y seguridad en el área.

- Generar un archivo inmobiliario que identifique los predios que conforman el sector donde se localizarán: edificaciones con tipología patrimonial a conservar, edificaciones susceptibles de demolición y/o cambio de uso.

\section{Referencias}

Martínez, E. (2001). Centros historicos en perspectiva. Observaciones sociologicas al analisis y planificacion territorial. Revista Catalana de socilogia, 87-103.

República de Colombia. Ministerio de Cultura. (2005). Manual de inventarios: Bienes culturales Inmuebles. Bogotá: Ministerio de Cultura. 
Romañas, J., Vidal, E., \& Rodriguez, L. (2014). Una mirada al suroccidente de barranquilla: Modulo Arquitectura CUC, 115-127.

Sarasa, A. (2005). Conflictos y estrategias en la gestion urbanistica de las ciudades historicas. Papeles de geografia, 29-49.

Secretaria de Planeacion de Barranquilla. (2012). Plan de desarrollo. Barranquilla: Alcaldia de Barranquilla.
Tello, M. I. (2008). Valoracion del patrimonio cultural construido. Paisajes e itinerarios culturales como estrategias de desarrollo. Bogotá: Restauradores sin fronteras.

Tello, M. (2013). El proyecto de conservación integral del patrimonio inmueble: Enfoques conceptuales, reflexiones valorativas y apuntes metodológicos. Modulo Arquitectura CUC, 99-130. 
INVENTARIO DE INMUEBLES PATRIMONIALES EN EL SECTOR CAÑOS DEL MERCADO PÚBLICO (Carrera 40 a 46 y calle 9 a calle 10) BARRANQUILLA

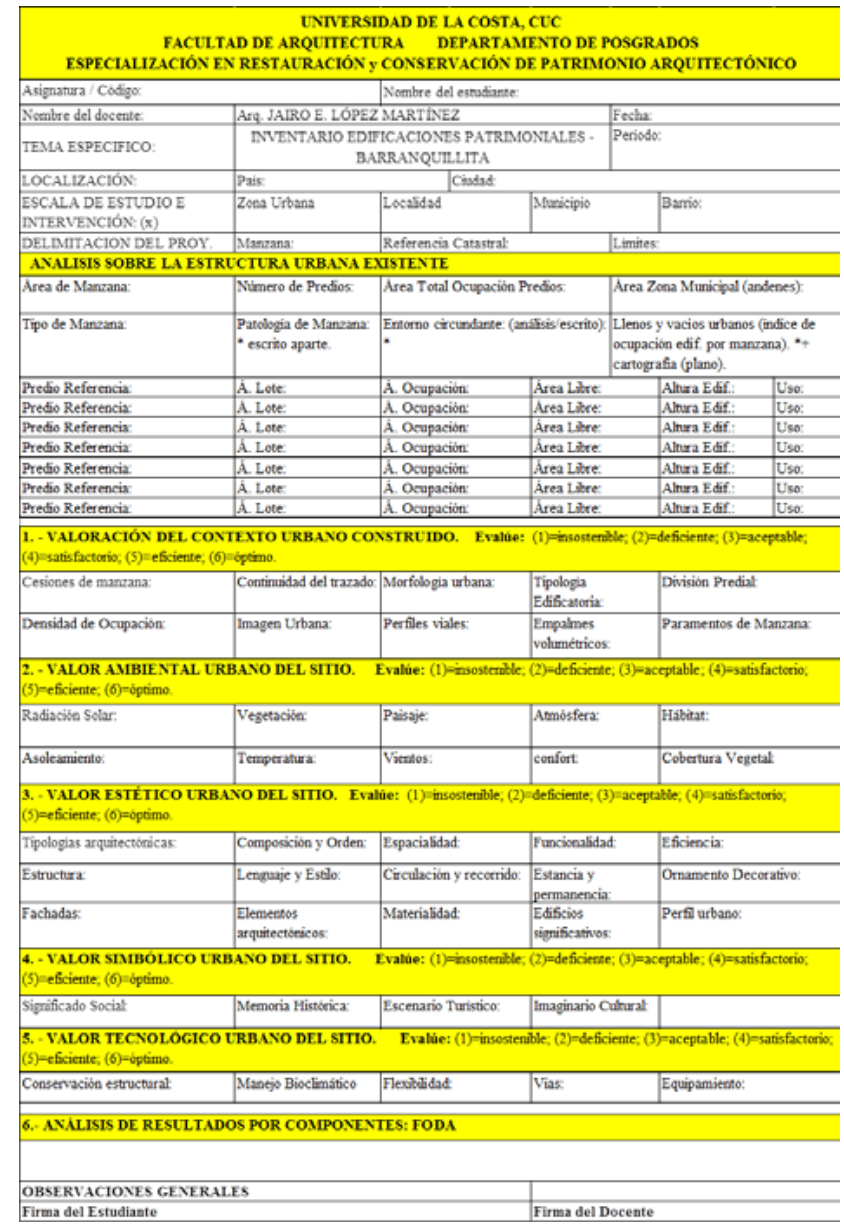

Anexo No.1 - Matriz trabajo de campo
INVENTARIO DE INMUEBLES PATRIMONIALES EN EL SECTOR CAÑOS DEL MERCADO PÚBLICO (Carrera 40 a 46 y calle 9 a calle 10) BARRANQUILLA
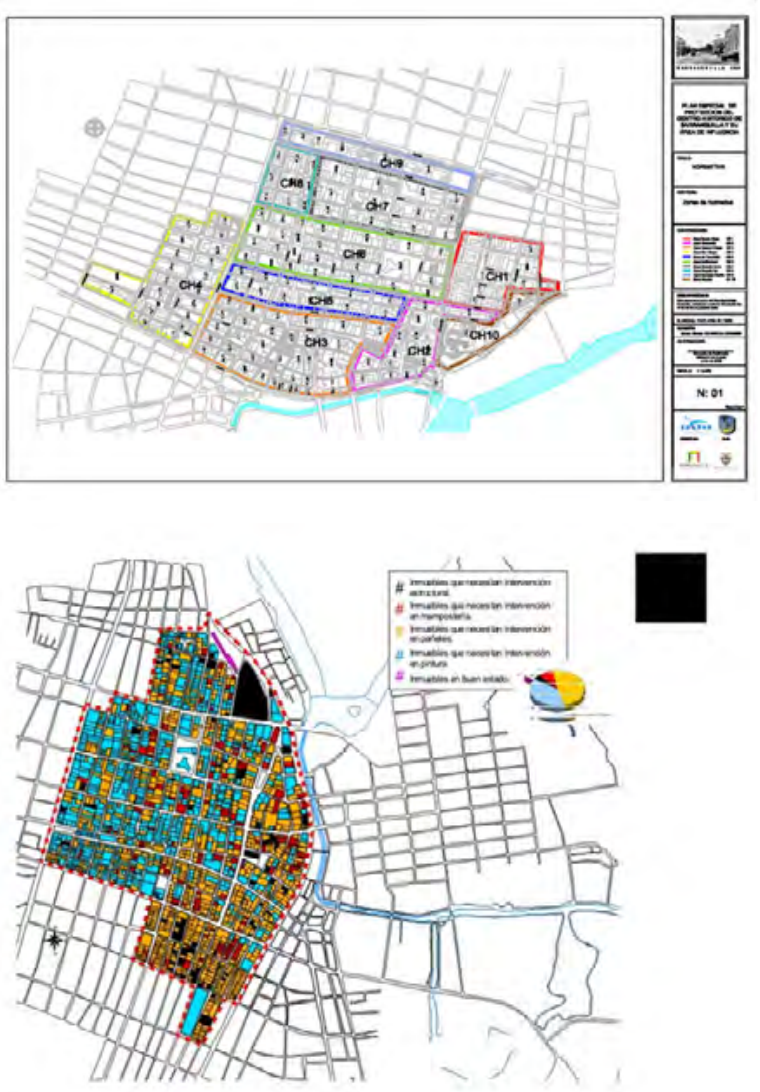

Anexo No.4 - Planos Delimitación del Centro Histórico de Barranquilla (POT - 2007) No incluye edificaciones del Sector de Barranquillita. 
INVENTARIO DE INMUEBLES PATRIMONIALES EN EL SECTOR CAÑOS DEL

MERCADO PÚBLICO (Carrera 40 a 46 y calle 9 a calle 10) BARRANQUILLA
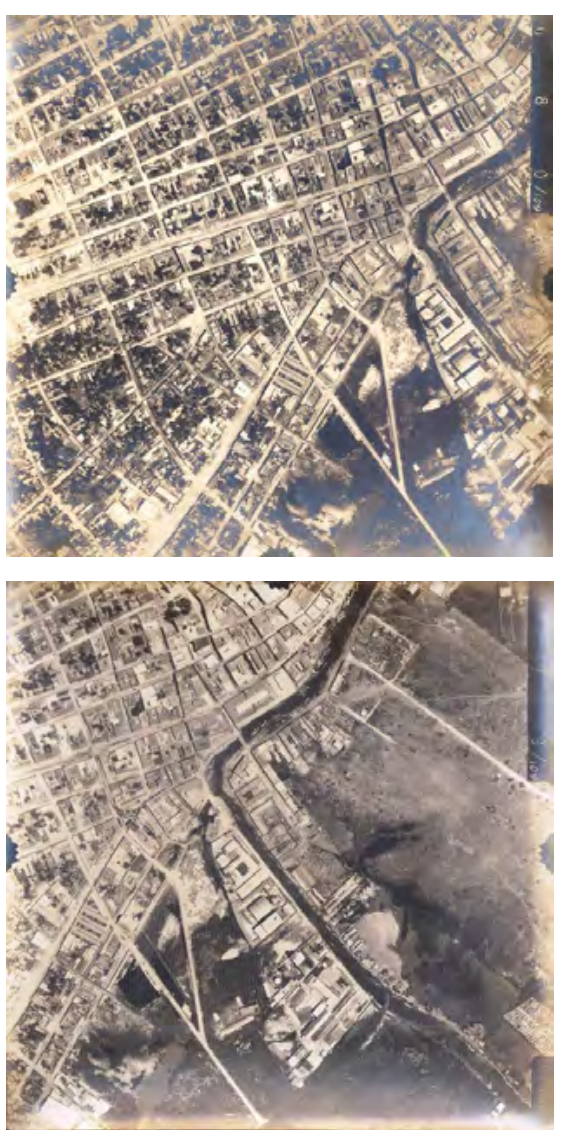

Anexo No.5 - Imágenes (1912) Sector de Barranquillita, Primeras Edificaciones. Manzanas 0328 , Nieto Arteta) Cortesía Arq. Juan P. Mestre H.
INVENTARIO DE INMUEBLES PATRIMONIALES EN EL SECTOR CAÑOS DEL

MERCADO PÚBLICO (Carrera 40 a 46 y calle 9 a calle 10) BARRANQUILLA
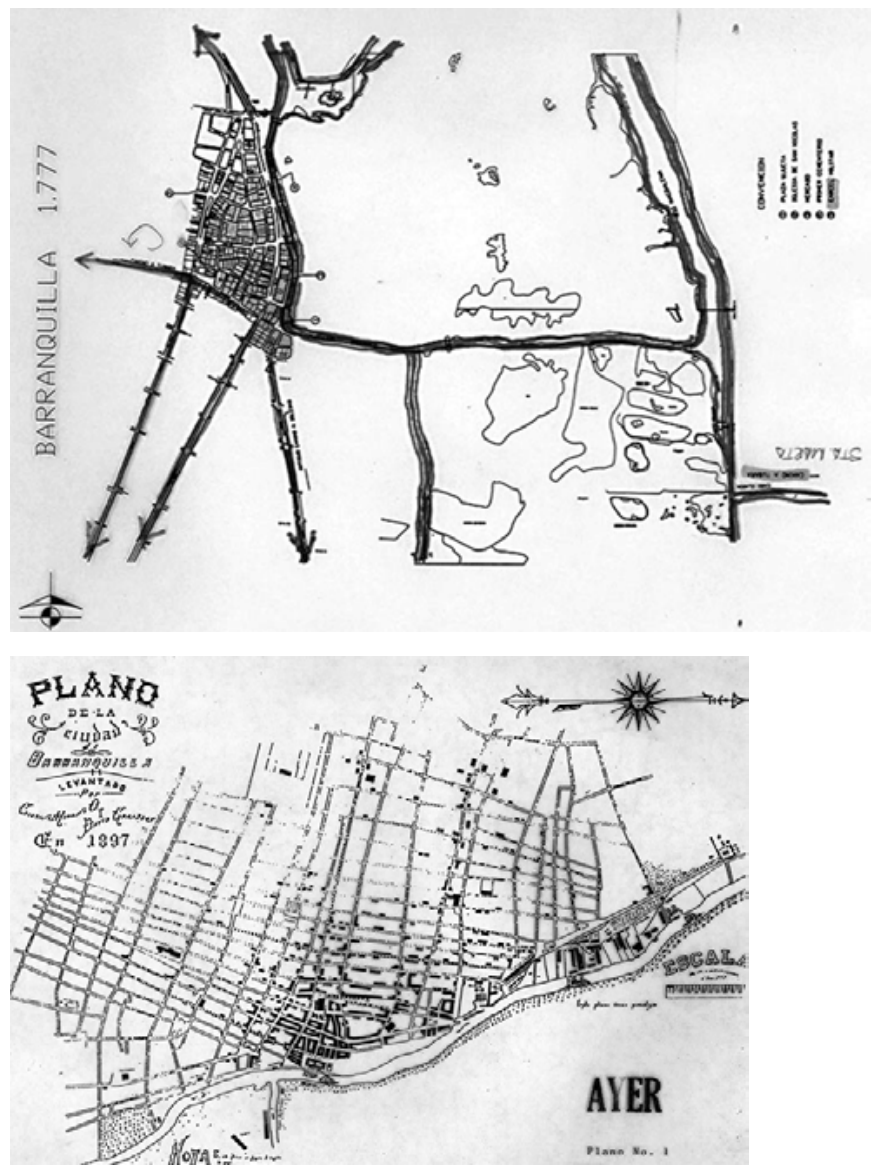

Anexo No.6 - Primer Plano de la ciudad (1777); Plano de 1897 más de un siglo en el tiempo, y el Sector de Barranquilita aún no despegaba por las tierras fangosas y anegadizas (solo el borde del caño se utilizaba para descargar mercancías). Imágenes archivo personal Arq. Porfirio Ospino C. 
INVENTARIO DE INMUEBLES PATRIMONIALES EN EL SECTOR CAÑOS DEL MERCADO PÚBLICO (Carrera 40 a 46 y calle 9 a calle 10) BARRANQUILLA

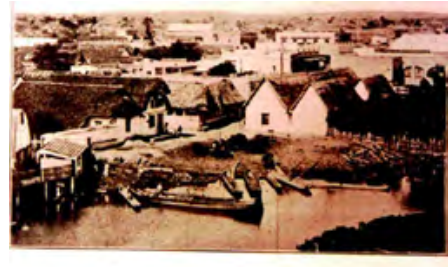

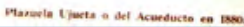

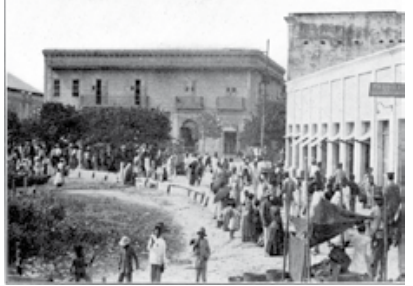

Plazuela Ujueta en 1912

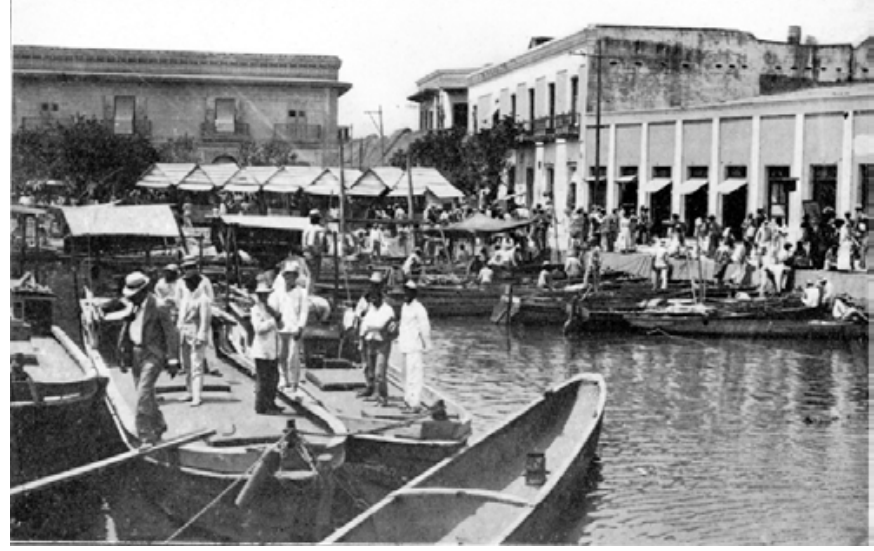

Plazuela Ujueta en 1920

Anexo No.7 - Sector de la Plazuela Ujueta, a través del tiempo (1880 - 1920). Hoy, aún conserva la dinámica de mercado y comercio.
INVENTARIO DE INMUEBLES PATRIMONIALES EN EL SECTOR CAÑOS DEL

MERCADO PÚBLICO (Carrera 40 a 46 y calle 9 a calle 10) BARRANQUILLA

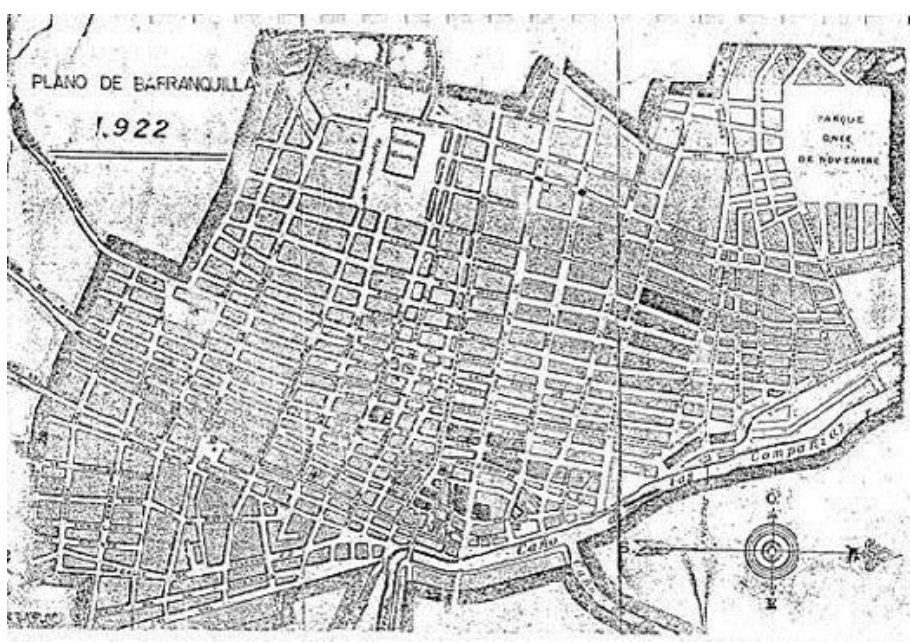

Plano de la ciudad (1922) Muestra el trazado del desarrollo urbano, y la visión de utilizar la franja oriental del Caño del Mercado.
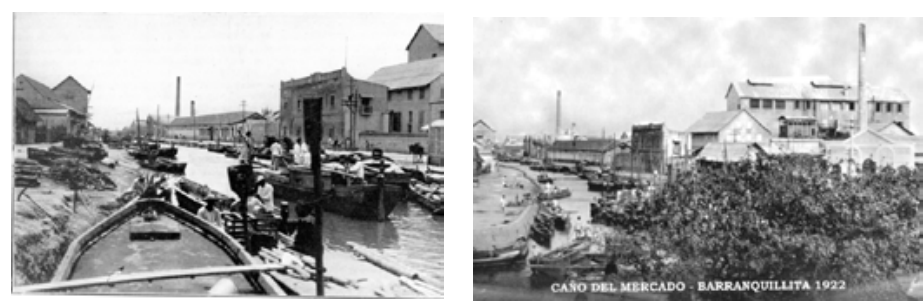

Anexo No.8 - Gráficas elocuentes de la funcionalidad y utilización del Caño arriba, Sector de la Cervecería Barranquilla. 
INVENTARIO DE INMUEBLES PATRIMONIALES EN EL SECTOR CAÑOS DEL MERCADO PÚBLICO (Carrera 40 a 46 y calle 9 a calle 10) BARRANQUILLA

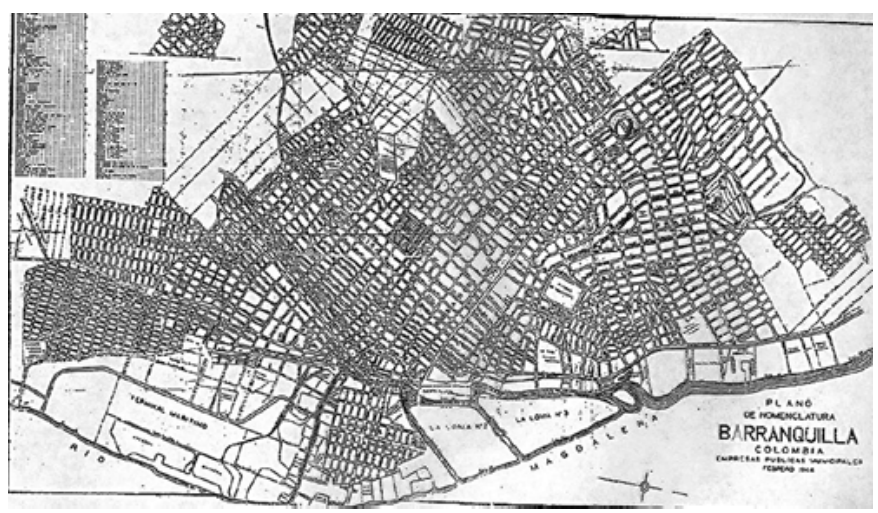

Plano de Barranquilla (1954)

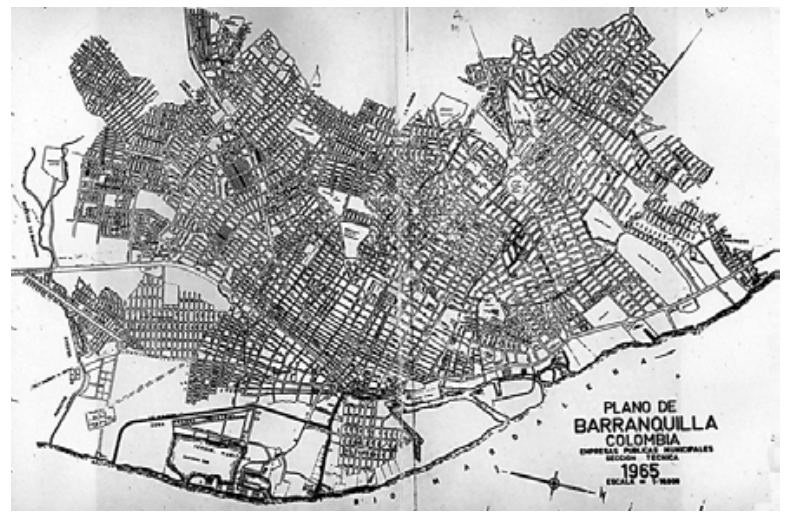

Plano de Barranquilla (1965)

Anexo No.9 - Planos de la ciudad (1954 - 1965) muestran el gran desarrollo urbano.
INVENTARIO DE INMUEBLES PATRIMONIALES EN EL SECTOR CAÑOS DEL MERCADO PÚBLICO (Carrera 40 a 46 y calle 9 a calle 10) BARRANQUILLA
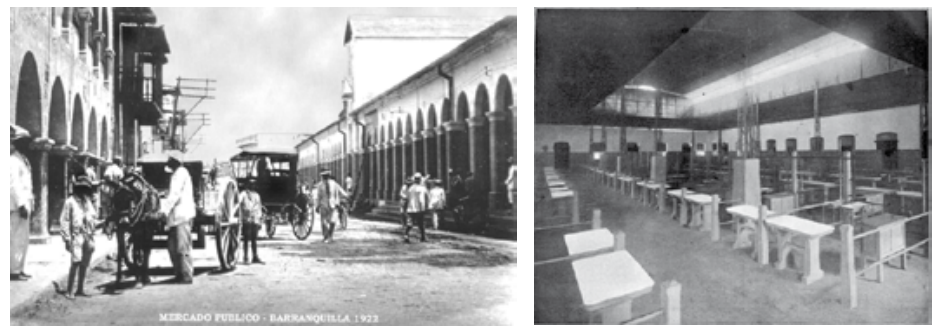

Calle 30 - Mercado Público - Armonía y limpieza exterior e interior (1922).

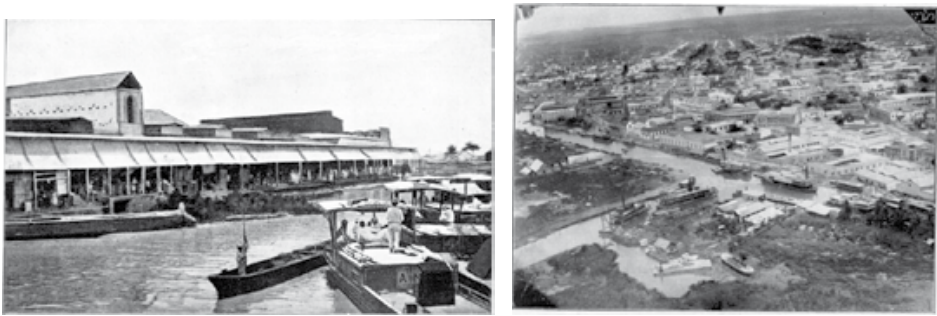

Mercado Público y su relación directa con los Caños. Eje de la navegación fluvial (1922).
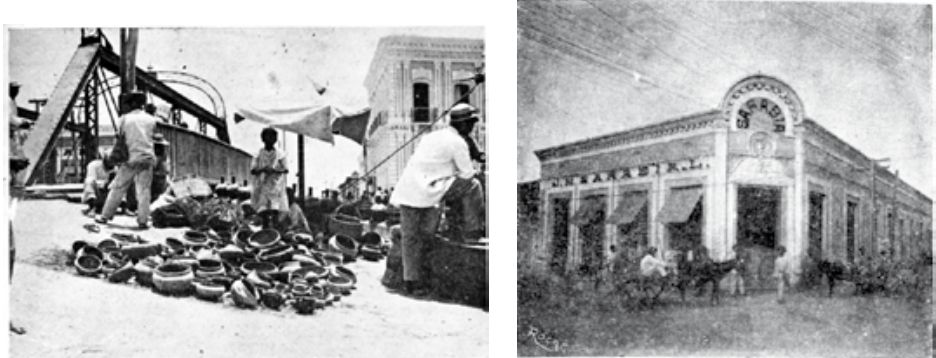

Anexo No.10 - Imágenes que muestran el desarrollo y progreso del Sector de Barranquillita. 
INVENTARIO DE INMUEBLES PATRIMONIALES EN EL SECTOR CAÑOS DEL MERCADO PÚBLICO (Carrera 40 a 46 y calle 9 a calle 10) BARRANQUILLA
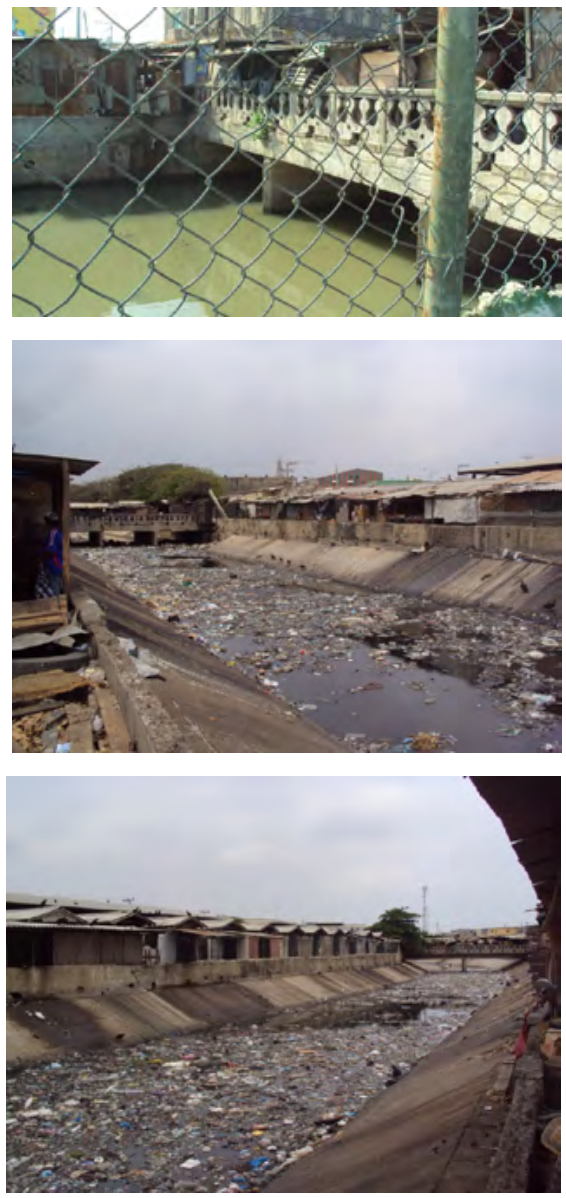

Anexo No.11 - Situación Medioambiental del cauce del Caño del Mercado (Estado actual) 2014situación insostenible. Imágenes: archivo personal Arq. Jairo López M.
INVENTARIO DE INMUEBLES PATRIMONIALES EN EL SECTOR CAÑOS DEL MERCADO PÚBLICO (Carrera 40 a 46 y calle 9 a calle 10) BARRANQUILLA
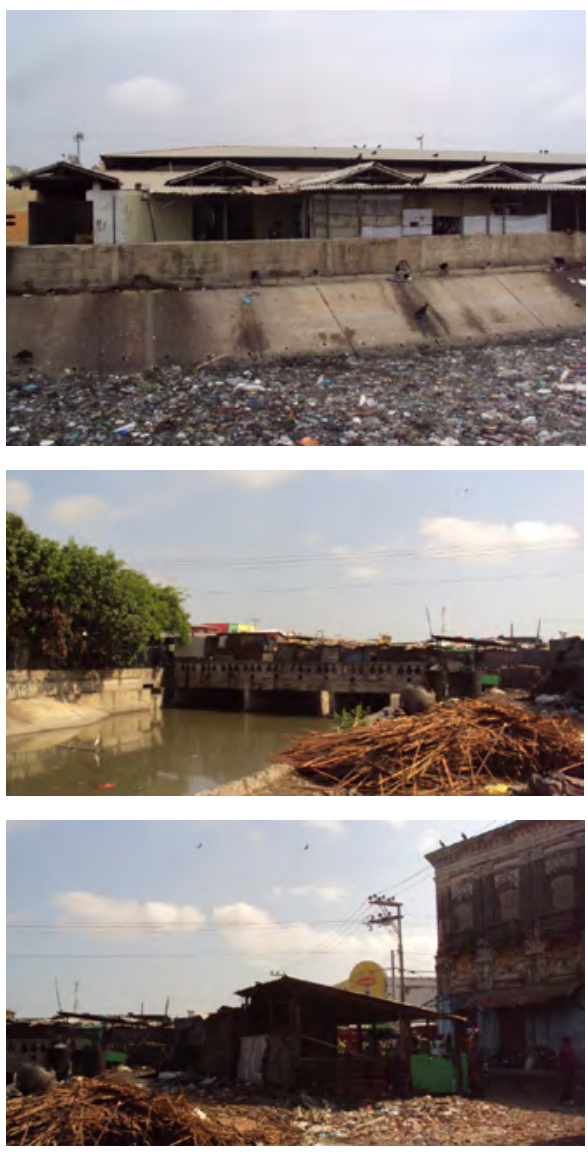

Anexo No.12 - Situación Medioambiental del cauce del Caño del Mercado (Estado actual) 2014 Situación insostenible. Degradación del espacio físico. Imágenes: archivo personal Arq. Jairo López M. 
INVENTARIO DE INMUEBLES PATRIMONIALES EN EL SECTOR CAÑOS DEL MERCADO PÚBLICO (CARRERA 40 A 46 Y CALLE 9 A CALLE 10) BARRANQUILLA
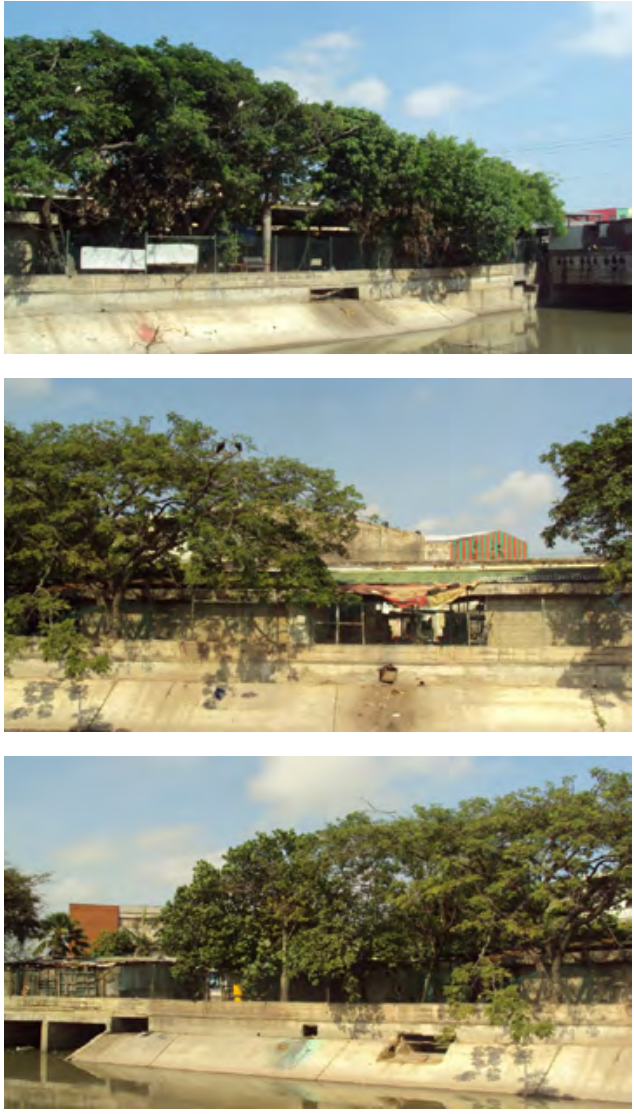

Anexo No.13 - Situación Medioambiental del cauce del Caño del Mercado (Estado actual) 2014 Vegetación nativa vs. Degradación del medio ambiente. Desagües sanitarios directos al caño. Imágenes: archivo personal Arq. Jairo López M.
INVENTARIO DE INMUEBLES PATRIMONIALES EN EL SECTOR CAÑOS DEL MERCADO PÚBLICO (Carrera 40 a 46 y calle 9 a calle 10) BARRANQUILLA
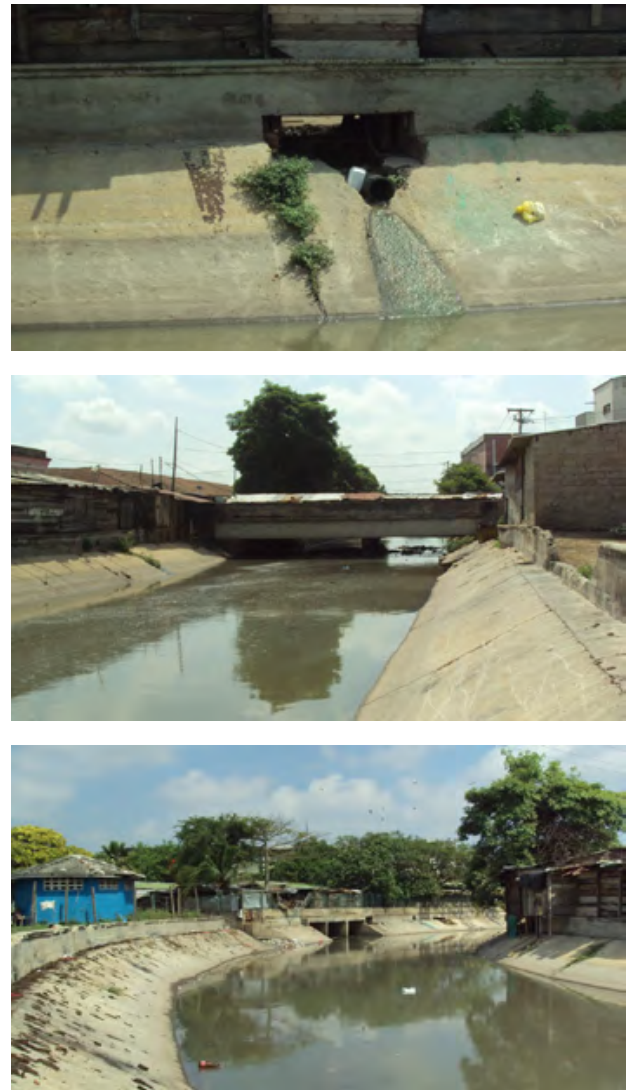

Anexo No.14 - Situación Medioambiental del cauce del Caño del Mercado (Estado actual) 2014 Faltan baños públicos. Lo que se observa son excrementos de gente habitantes de la calle. Imágenes: archivo personal Arq. Jairo López M. 
INVENTARIO DE INMUEBLES PATRIMONIALES EN EL SECTOR CAÑOS DEL MERCADO PÚBLICO (Carrera 40 a 46 y calle 9 a calle 10) BARRANQUILLA
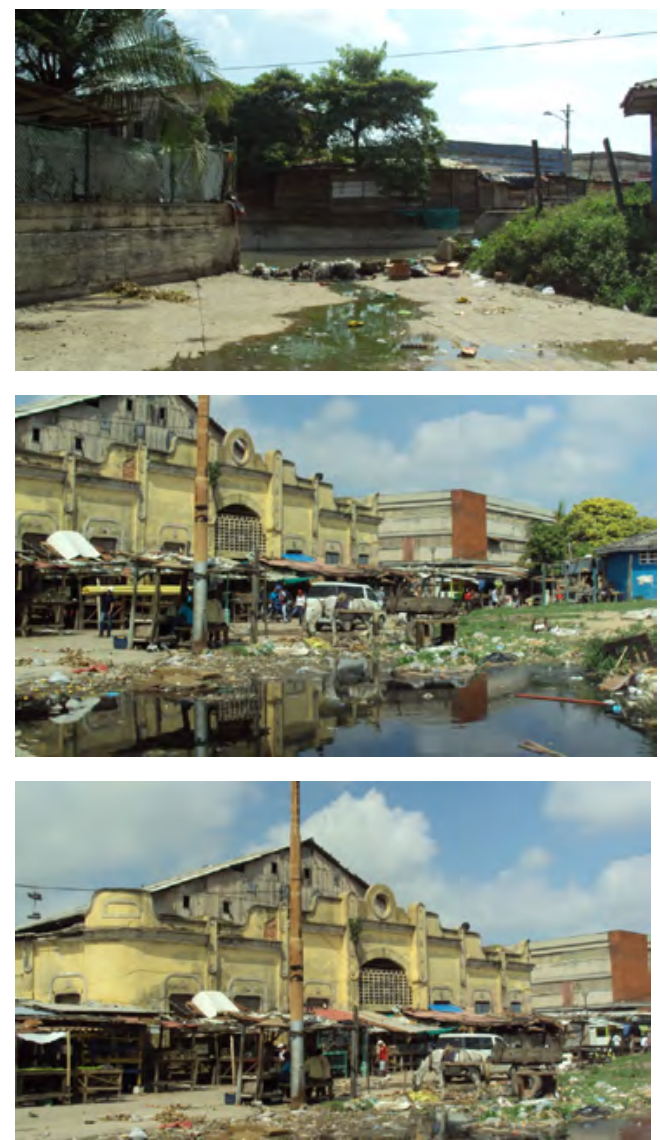

Anexo No.15 - Situación Medioambiental del cauce del Caño del Mercado (Estado actual) 2014 Mejoramiento en plan recolección basuras. Al Fondo Edificio del Mercado de Granos. Imágenes: archivo personal Arq. Jairo López M.
INVENTARIO DE INMUEBLES PATRIMONIALES EN EL SECTOR CAÑOS DEL MERCADO PÚBLICO (Carrera 40 a 46 y calle 9 a calle 10) BARRANQUILLA
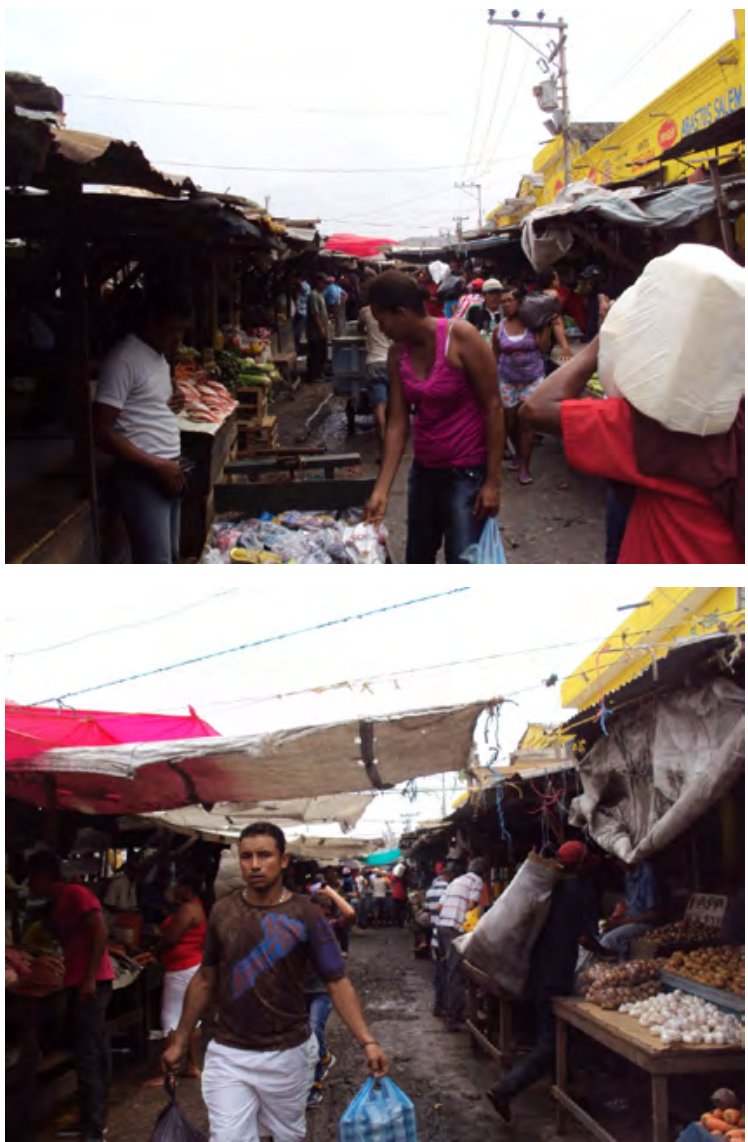

Anexo No.16 - Situación: Calle 10 - Carreras 41B y 42D Borde - Caño del Mercado (Estado actual) 2014 - Ocupación de espacio público, Ventas estacionarias, ambulantes, inclusive vivienda. Imágenes: archivo personal Arq. Jairo López M. 
INVENTARIO DE INMUEBLES PATRIMONIALES EN EL SECTOR CAÑOS DEL

MERCADO PÚBLICO (Carrera 40 a 46 y calle 9 a calle 10) BARRANQUILLA
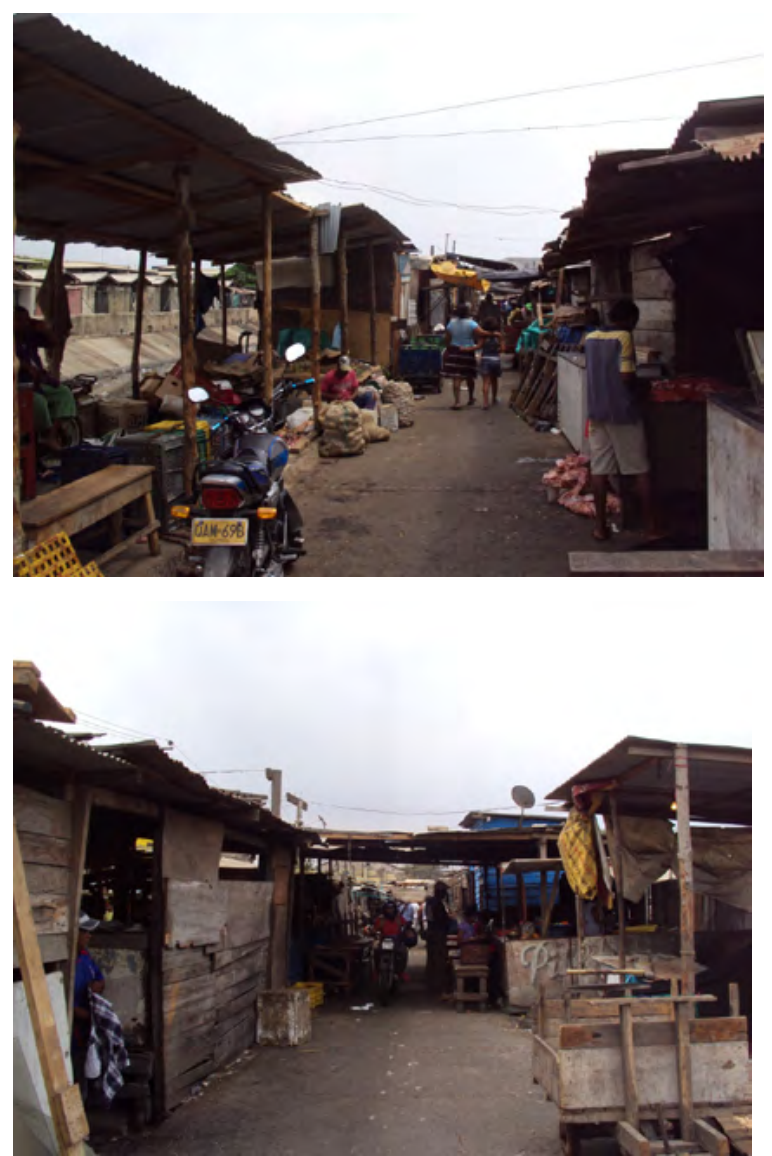

Anexo No.17 - Situación: Calle 10 - Carreras 41B y 42D Borde - Caño del Mercado (Estado actual) 2014 - Ocupación de espacio público, vivienda sobre andenes y calle interior (atracadero). Imágenes: archivo personal Arq. Jairo López M.
INVENTARIO DE INMUEBLES PATRIMONIALES EN EL SECTOR CAÑOS DEL

MERCADO PÚBLICO (Carrera 40 a 46 y calle 9 a calle 10) BARRANQUILLA

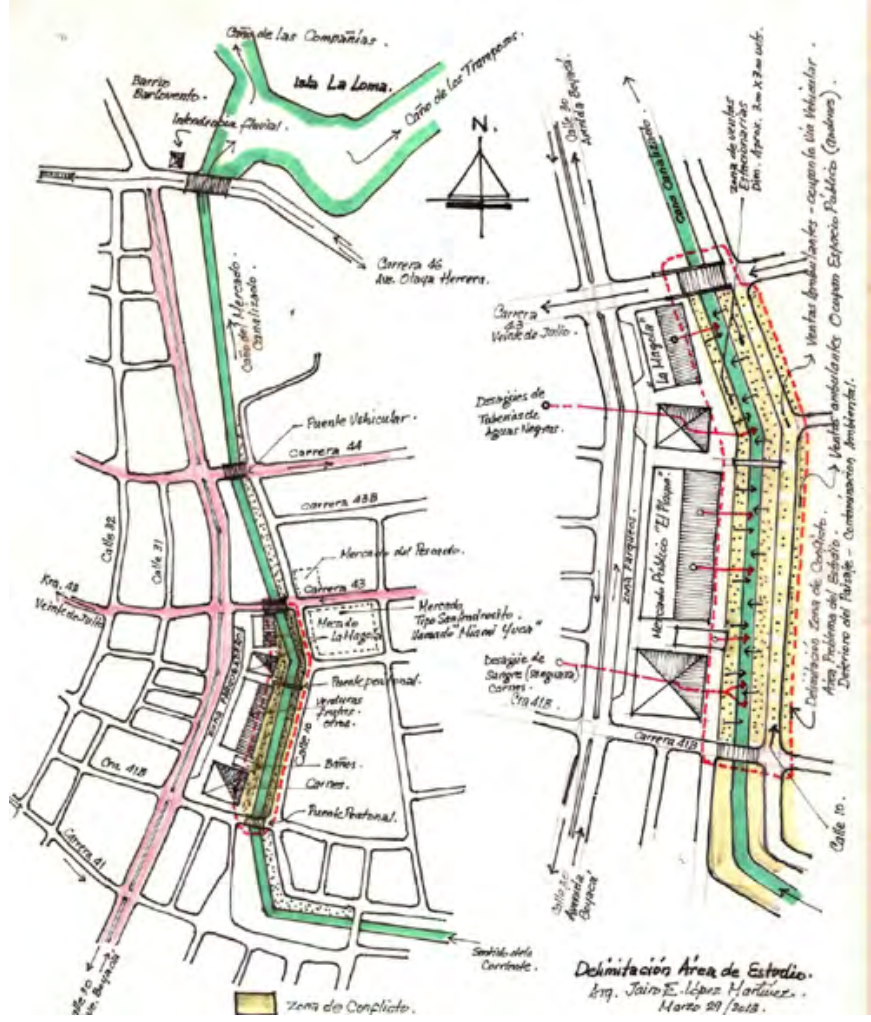

Anexo No.18 - Situación: Calle 10 - Carreras 41B y 42D Borde - Caño del Mercado (Estado actual) 2014 - Esquema de Ocupación espacio público y generación de residuos (basuras). Imágenes: archivo personal Arq. Jairo López M. 
INVENTARIO DE INMUEBLES PATRIMONIALES EN EL SECTOR CAÑOS DEL MERCADO PÚBLICO (Carrera 40 a 46 y calle 9 a calle 10) BARRANQUILLA
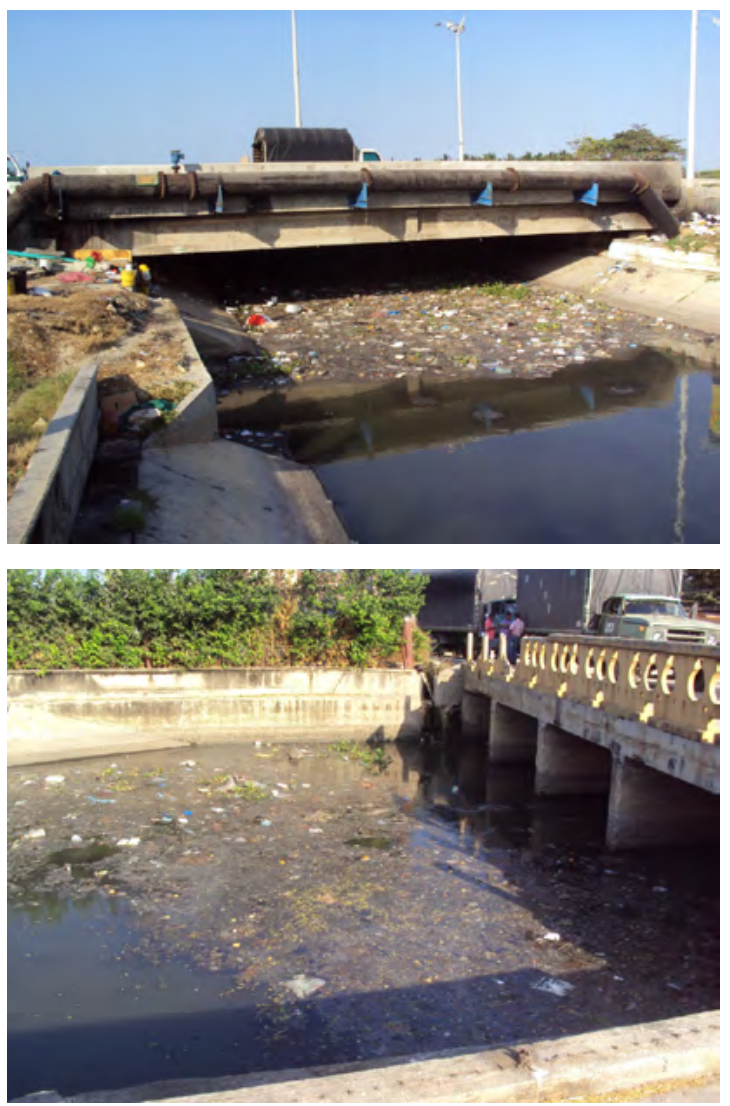

Anexo No.19 - Situación: Calle 10 - Carreras 41B y 42D Borde - Caño del Mercado (Estado actual) 2014. Degradación del medio ambiente.
INVENTARIO DE INMUEBLES PATRIMONIALES EN EL SECTOR CAÑOS DEL MERCADO PÚBLICO (Carrera 40 a 46 y calle 9 a calle 10) BARRANQUILLA

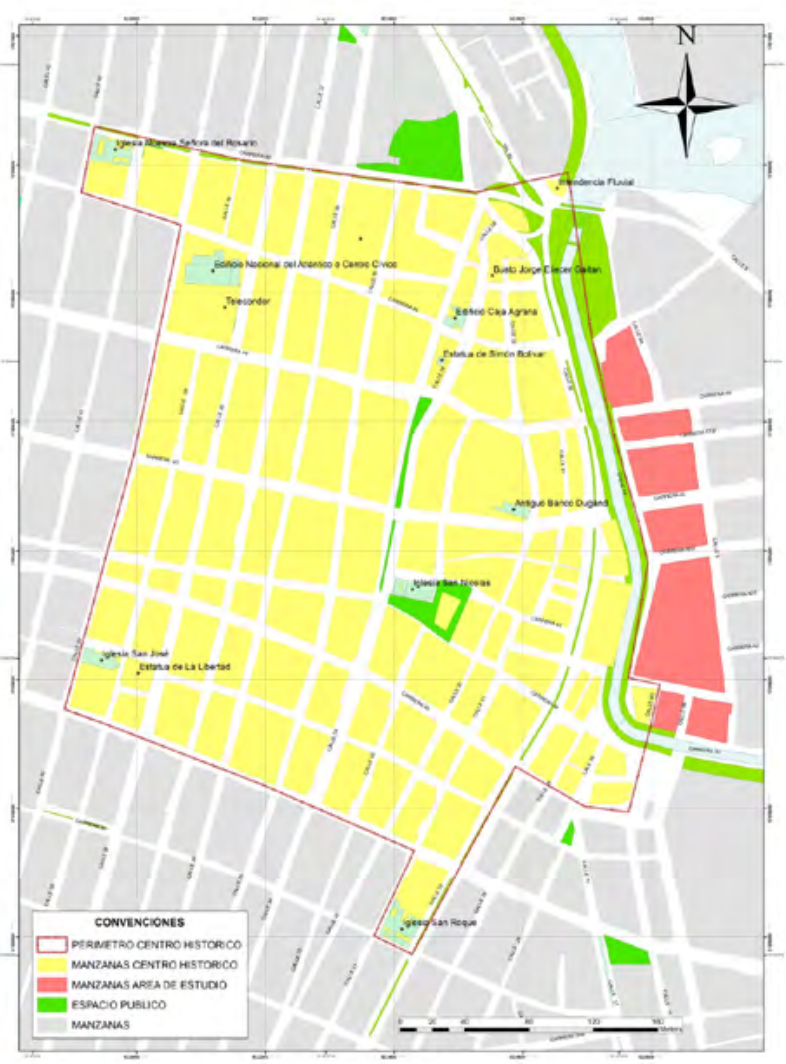

PLANO No. 01 - Plano del Centro Histórico (Incluye en su perímetro la única edificación patrimonial de carácter excepcional en el sector de Barranquillita - Manzana 0328; Carrera $41 \mathrm{~N}$ a Carrera $41 \mathrm{~B}$; Calle $9 \mathrm{C}$ a Calle 10 ) 
INVENTARIO DE INMUEBLES PATRIMONIALES EN EL SECTOR CAÑOS DEL MERCADO PÚBLICO (Carrera 40 a 46 y calle 9 a calle 10) BARRANQUILLA

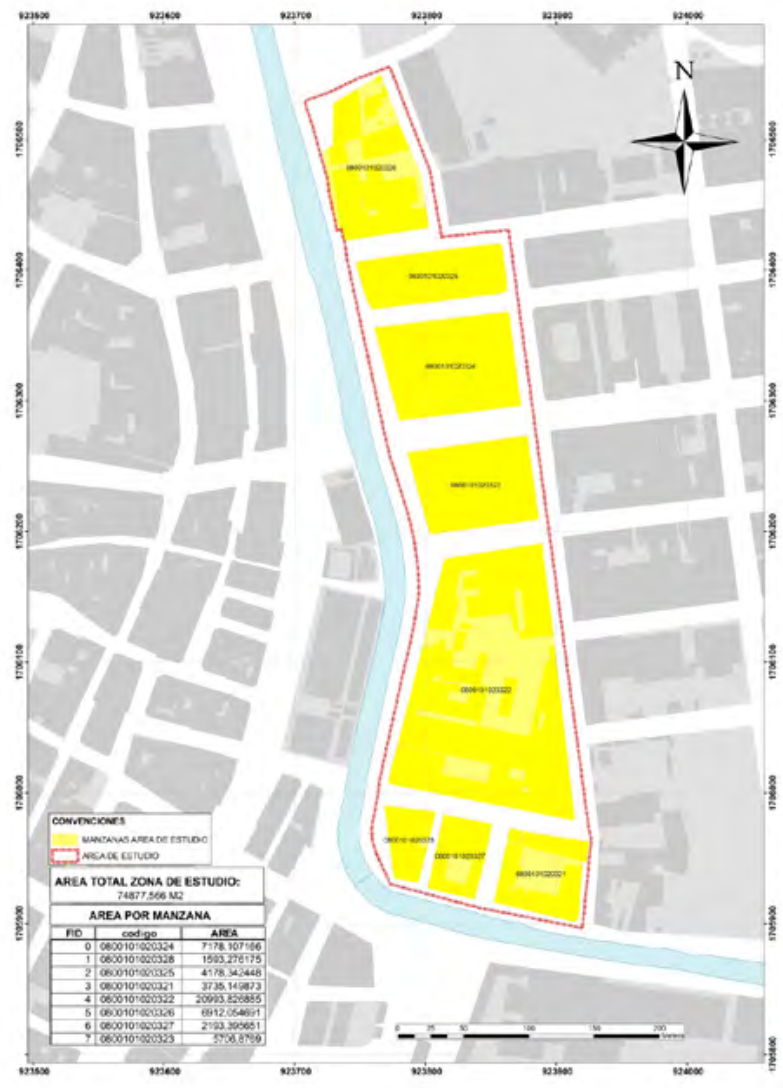

PLANO No. 02 - Plano del Sector de Estudio (Incluye referencias catastrales por manzana y su respectiva área.
INVENTARIO DE INMUEBLES PATRIMONIALES EN EL SECTOR CAÑOS DEL MERCADO PÚBLICO (Carrera 40 a 46 y calle 9 a calle 10) BARRANQUILLA

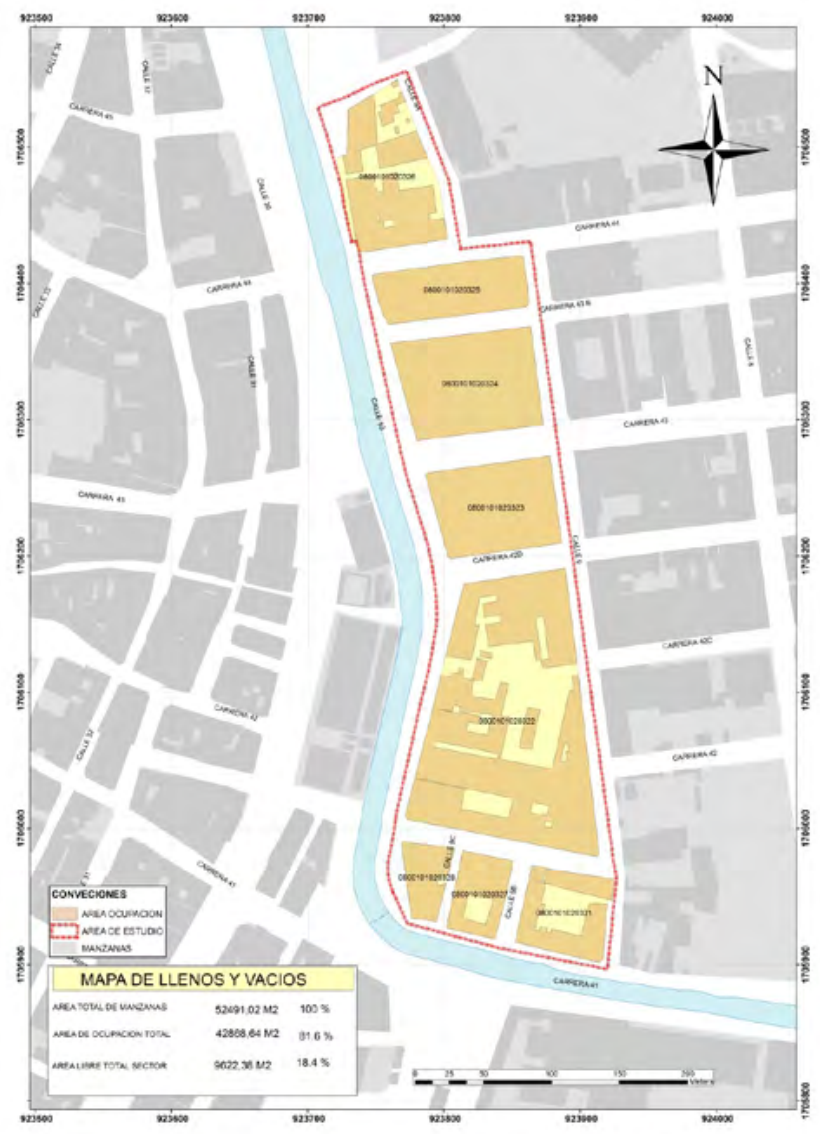

PLANO No. 03 - Plano del Sector de Estudio - LLENOS Y VACIOS. 
INVENTARIO DE INMUEBLES PATRIMONIALES EN EL SECTOR CAÑOS DEL MERCADO PÚBLICO (Carrera 40 a 46 y calle 9 a calle 10) BARRANQUILLA

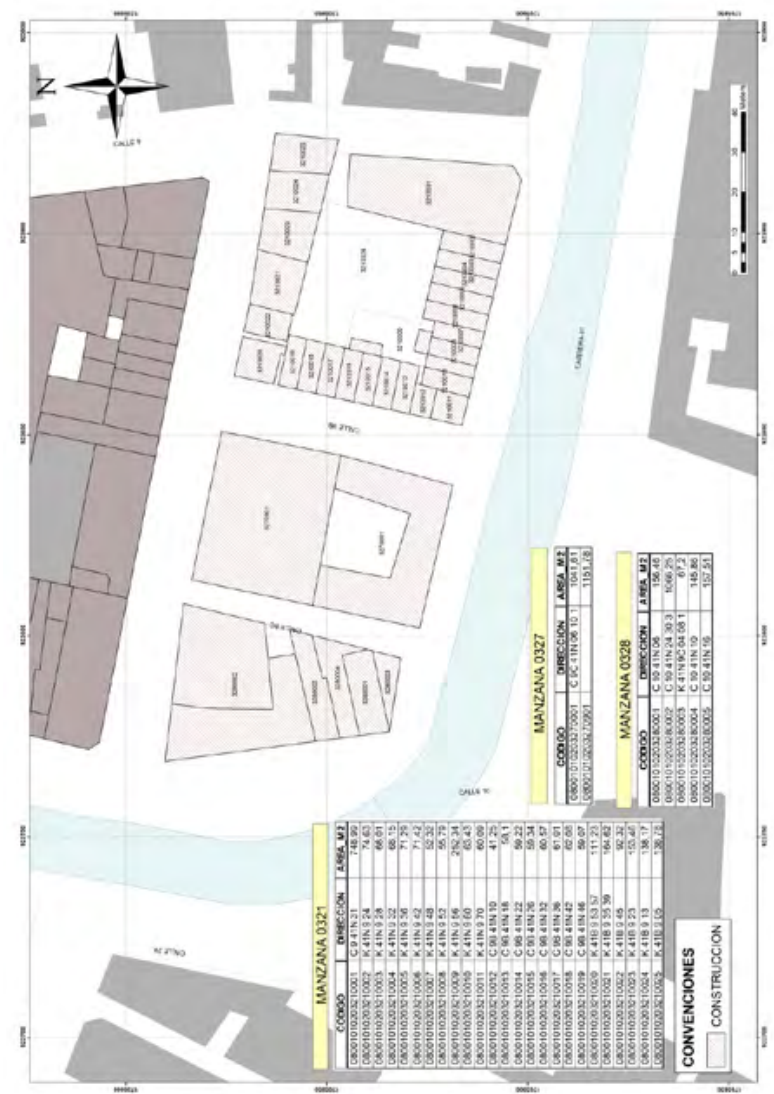

PLANO No. 04 - Plano del Sector de Estudio: Manzanas: 0321; 0327 y 0328 (Referencia catastral de predios; Dirección y Área).
INVENTARIO DE INMUEBLES PATRIMONIALES EN EL SECTOR CAÑOS DEL

MERCADO PÚBLICO (Carrera 40 a 46 y calle 9 a calle 10) BARRANQUILLA

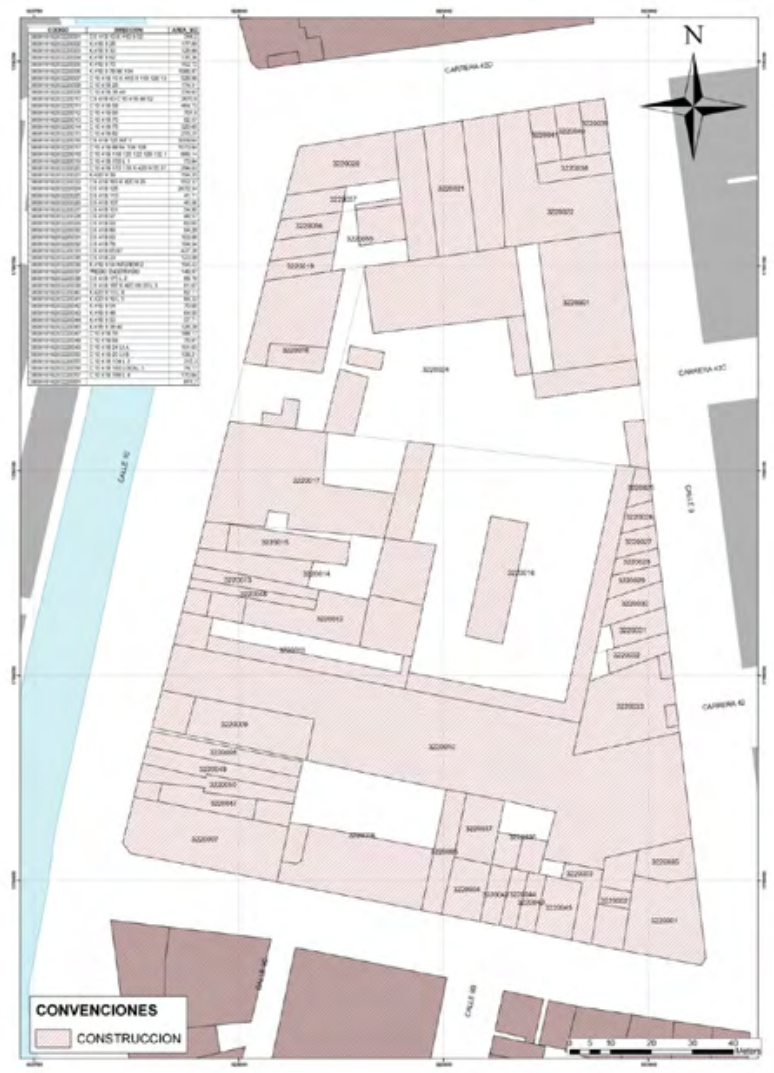

PLANO No. 05 - Plano del Sector de Estudio: Manzanas: 0322 (Referencia catastral de predios; Dirección y Área). 
INVENTARIO DE INMUEBLES PATRIMONIALES EN EL SECTOR CAÑOS DEL MERCADO PÚBLICO (Carrera 40 a 46 y calle 9 a calle 10) BARRANQUILLA

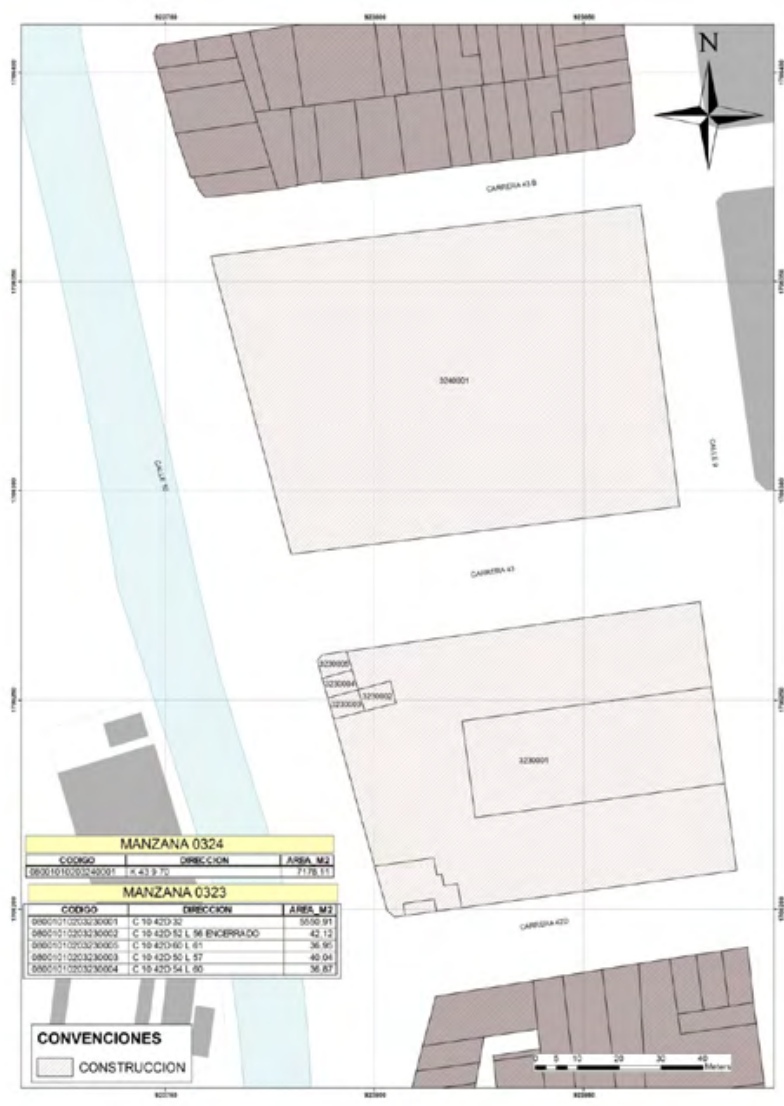

PLANO No. 06 - Plano del Sector de Estudio: Manzanas: 0323 y 0324 (Referencia catastral de predios; Dirección y Área).
INVENTARIO DE INMUEBLES PATRIMONIALES EN EL SECTOR CAÑOS DEL MERCADO PÚBLICO (Carrera 40 a 46 y calle 9 a calle 10) BARRANQUILLA

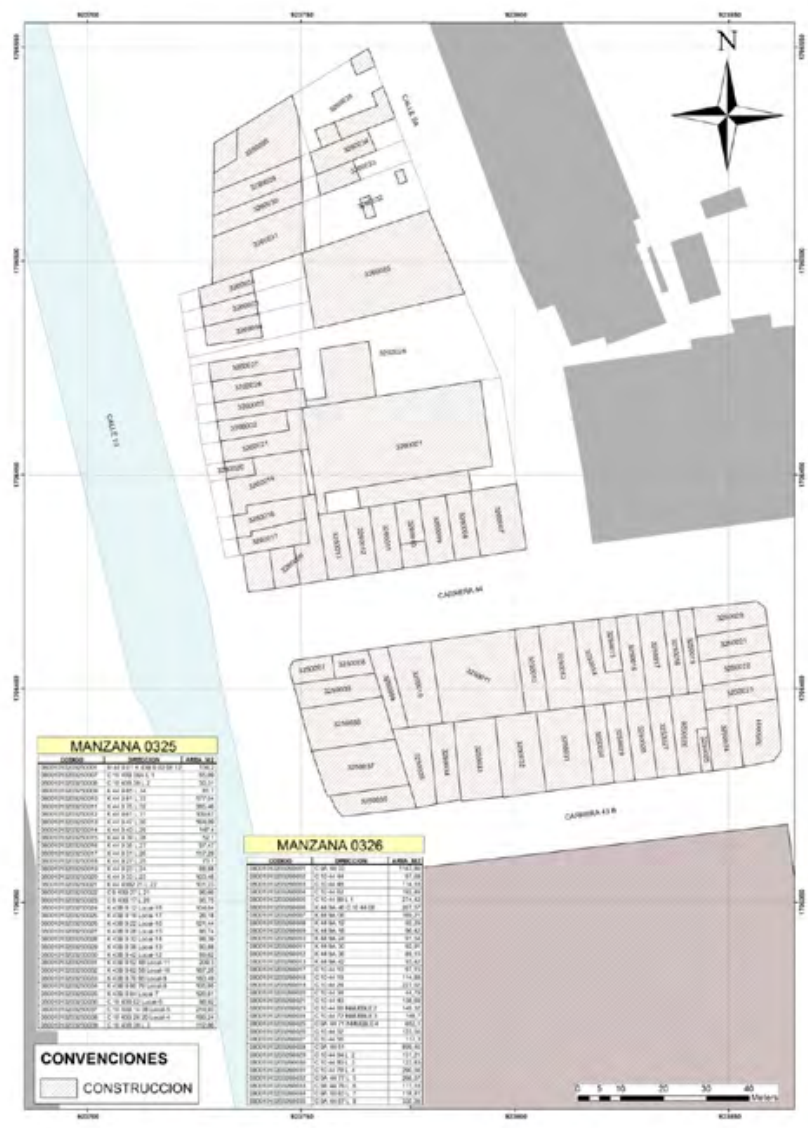

PLANO No. 07 - Plano del Sector de Estudio: Manzanas: 0325 y 0326 (Referencia catastral de predios; Dirección y Área). 
INVENTARIO DE INMUEBLES PATRIMONIALES EN EL SECTOR CAÑOS DEL MERCADO PÚBLICO (Carrera 40 a 46 y calle 9 a calle 10) BARRANQUILLA

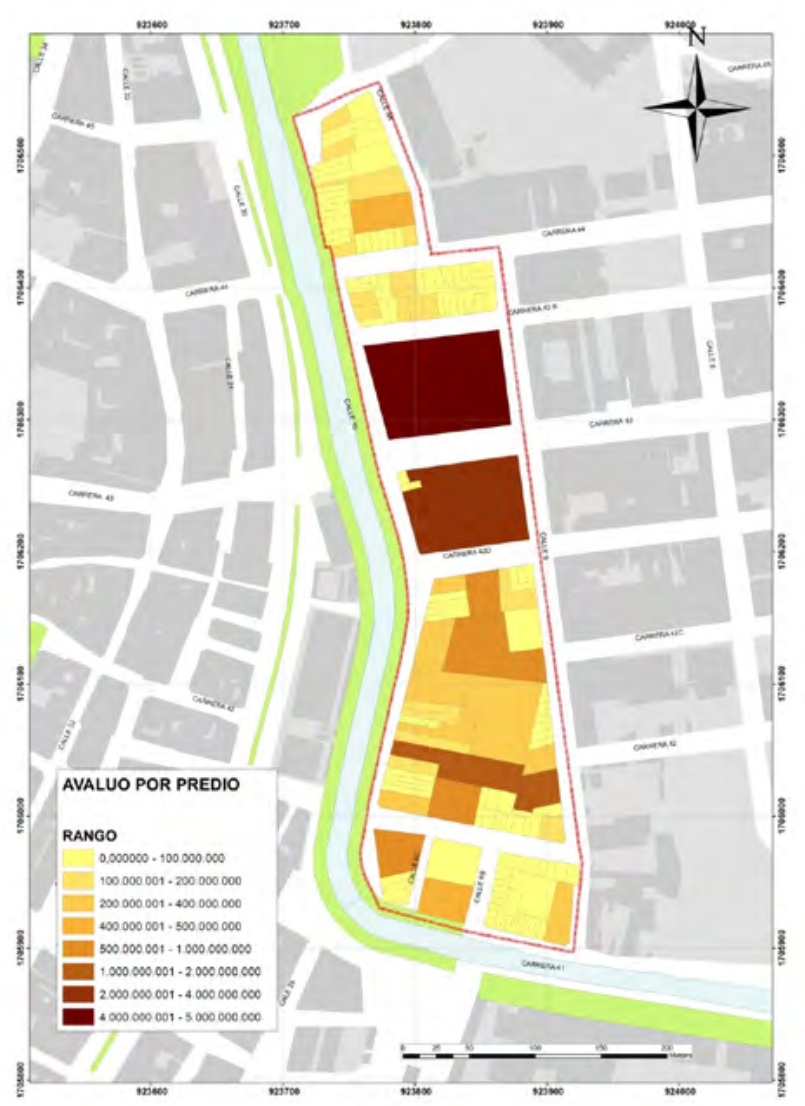

PLANO No. 08 - Plano del Sector de Estudio: Manzanas: 0321; 0327 y 0328; 0322; 0323 0324; 0325 y 0326 (Rangos de avalúos de predios) - Fuente S.C.A. Regional Atlántico. 